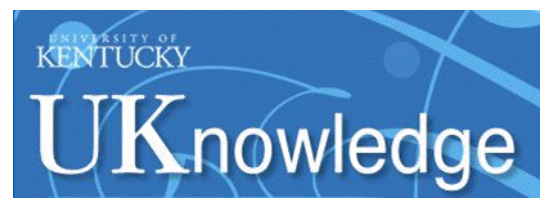

University of Kentucky

UKnowledge

$10-6-2014$

\title{
Governmental Public Health and the Economics of Adaptation to Population Health
}

\author{
Glen P. Mays \\ University of Kentucky, glen.mays@cuanschutz.edu
}

Follow this and additional works at: https://uknowledge.uky.edu/hsm_present

Part of the Health and Medical Administration Commons, Health Economics Commons, and the Health Services Research Commons

Right click to open a feedback form in a new tab to let us know how this document benefits you.

\section{Repository Citation}

Mays, Glen P., "Governmental Public Health and the Economics of Adaptation to Population Health" (2014). Health Management and Policy Presentations. 74.

https://uknowledge.uky.edu/hsm_present/74

This Presentation is brought to you for free and open access by the Health Management and Policy at UKnowledge. It has been accepted for inclusion in Health Management and Policy Presentations by an authorized administrator of UKnowledge. For more information, please contact UKnowledge@lsv.uky.edu. 


\section{Governmental Public Health and the Economics of Adaptation to Population Health}

Glen Mays, PhD, MPH

University of Kentucky

glen.mays@uky.edu

British Columbia Population Health Network ～～6 October 2014 


\section{Overview}

ص How can systems research inform transformation in public health?

- Examples of systems research in public health

- Delivery system organization \& structure

- Finance and economics

v Resources for advancing the field

n Opportunities and challenges for the future 


\section{Failures in population health}

Figure 1. There are large differences in life expectancy and health care spending across OECD countries $2008^{1}$

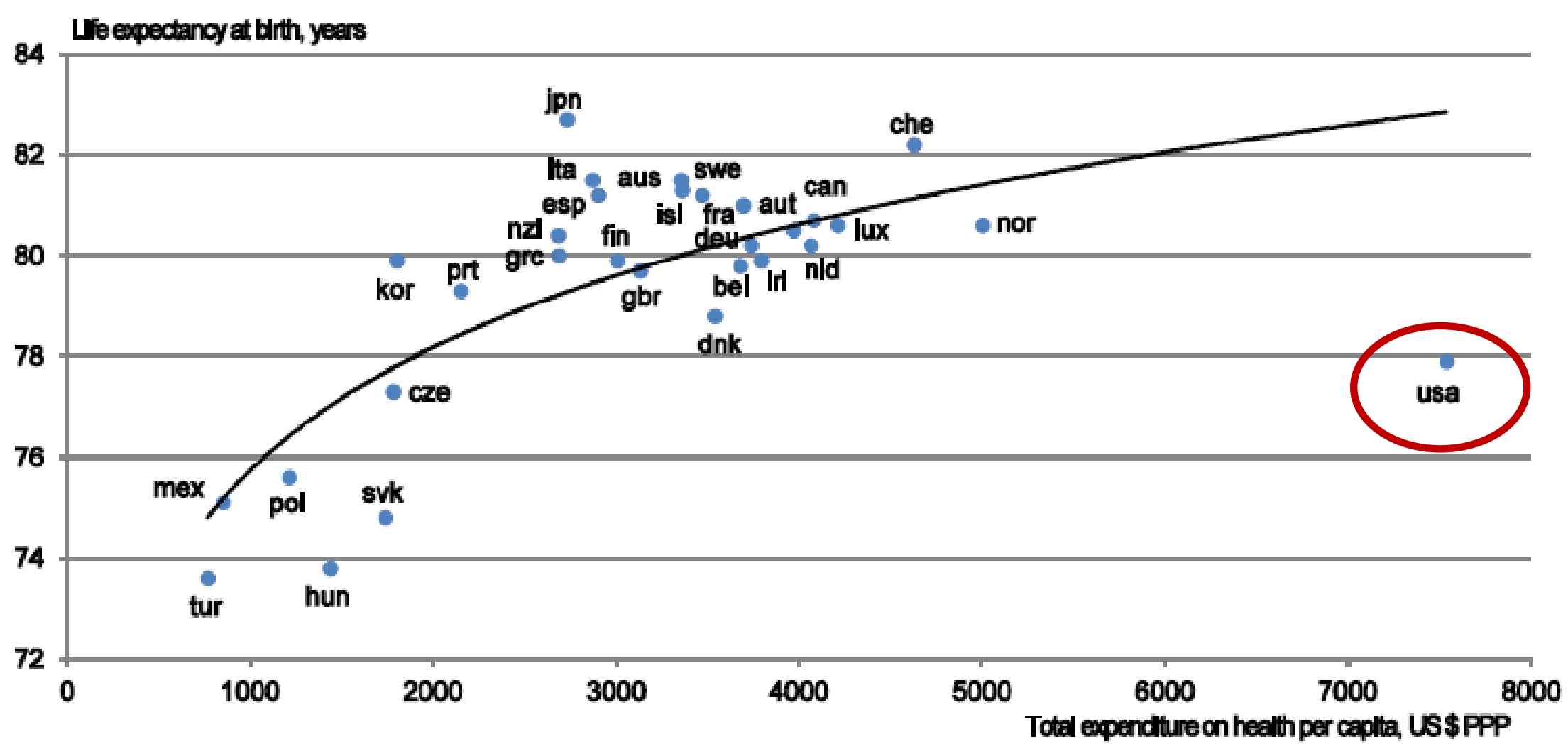

1. Or latest year available.

Source: OECD Health Data 2010. 


\section{Drivers of population health failures}

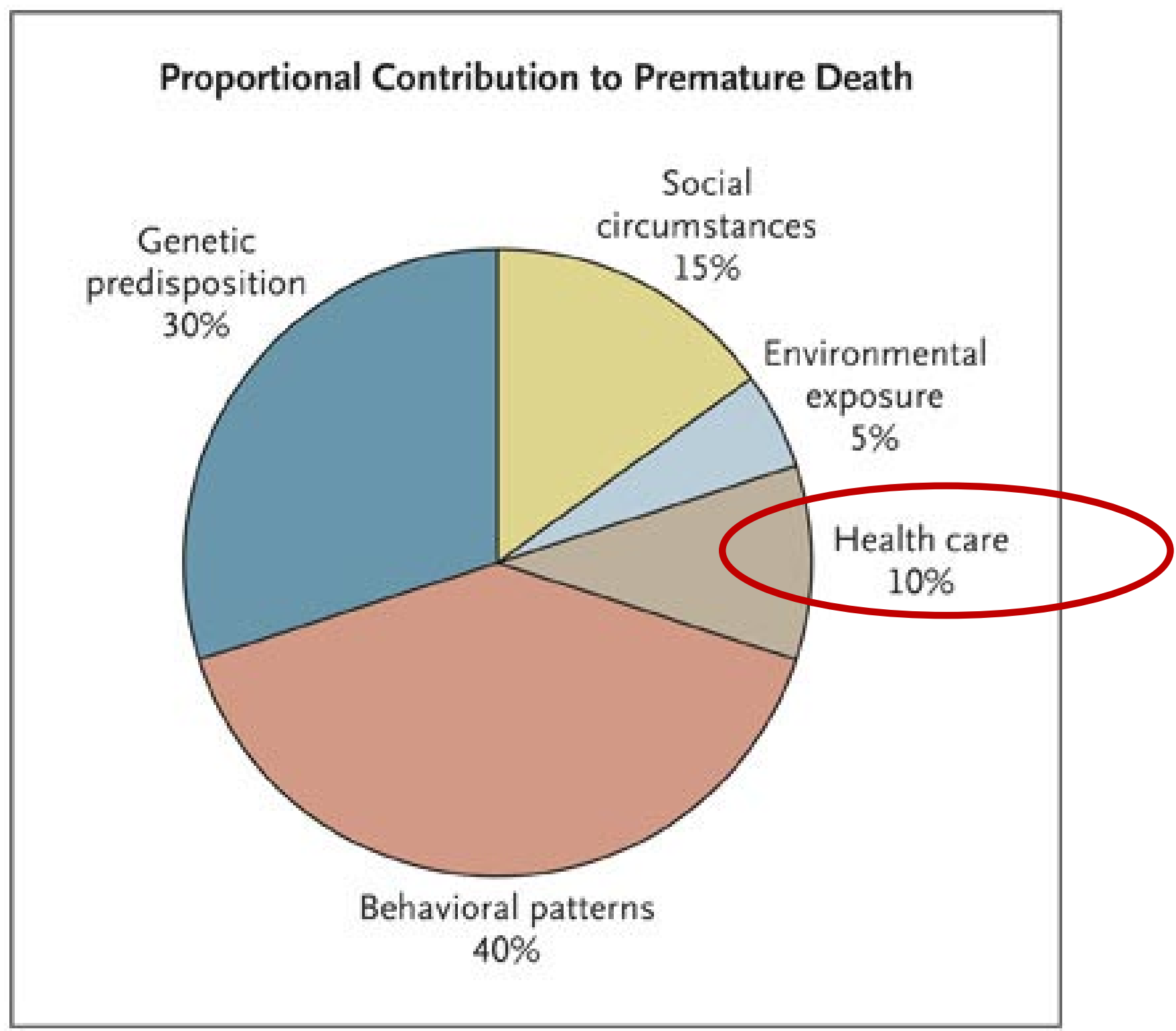

Schroeder SA. N Engl J Med 2007;357:1221-1228 


\section{Public health services \& systems research}

A field of inquiry examining the organization, financing, and delivery of public health services at local, state and national levels, and the impact of these activities on population health

Strategies to promote health and prevent disease \& injury on a population-wide basis: programs, policies, administrative practices 


\section{A Key PHSSR Goal: Optimization}

How to optimally deploy a diverse collection of responsibilities, resources, actors \& expectations?

- Epidemiologic surveillance \& investigation

- Community health assessment \& planning

- Communicable disease control

- Chronic disease and injury prevention

- Health education and communication

- Environmental health monitoring and assessment

- Enforcement of health laws and regulations

- Inspection and licensing

- Inform, advise, and assist school-based, worksite-based, and community-based health programming

... and roles in assuring access to medical care

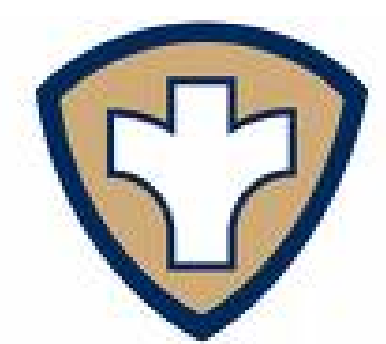

Promote. Protect. 


\section{PHSSR's place in the continuum}

\section{Intervention}

Research

\section{Services/Systems}

Research

- What works - proof of efficacy

- Controlled trials

- Guide to Community Preventive Services

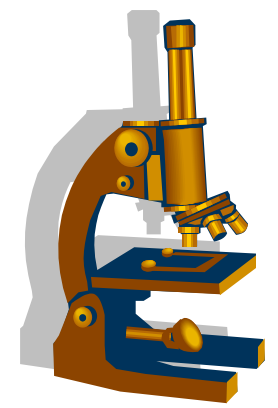

- How to organize, implement and sustain in the real-world

- Reach

- Enforcement/Compliance

- Quality/Effectiveness

- Cost/Efficiency

- Equity/Disparities

- Impact on population health

- Comparative effectiveness \& efficiency 


\section{Complexity in public health delivery systems}

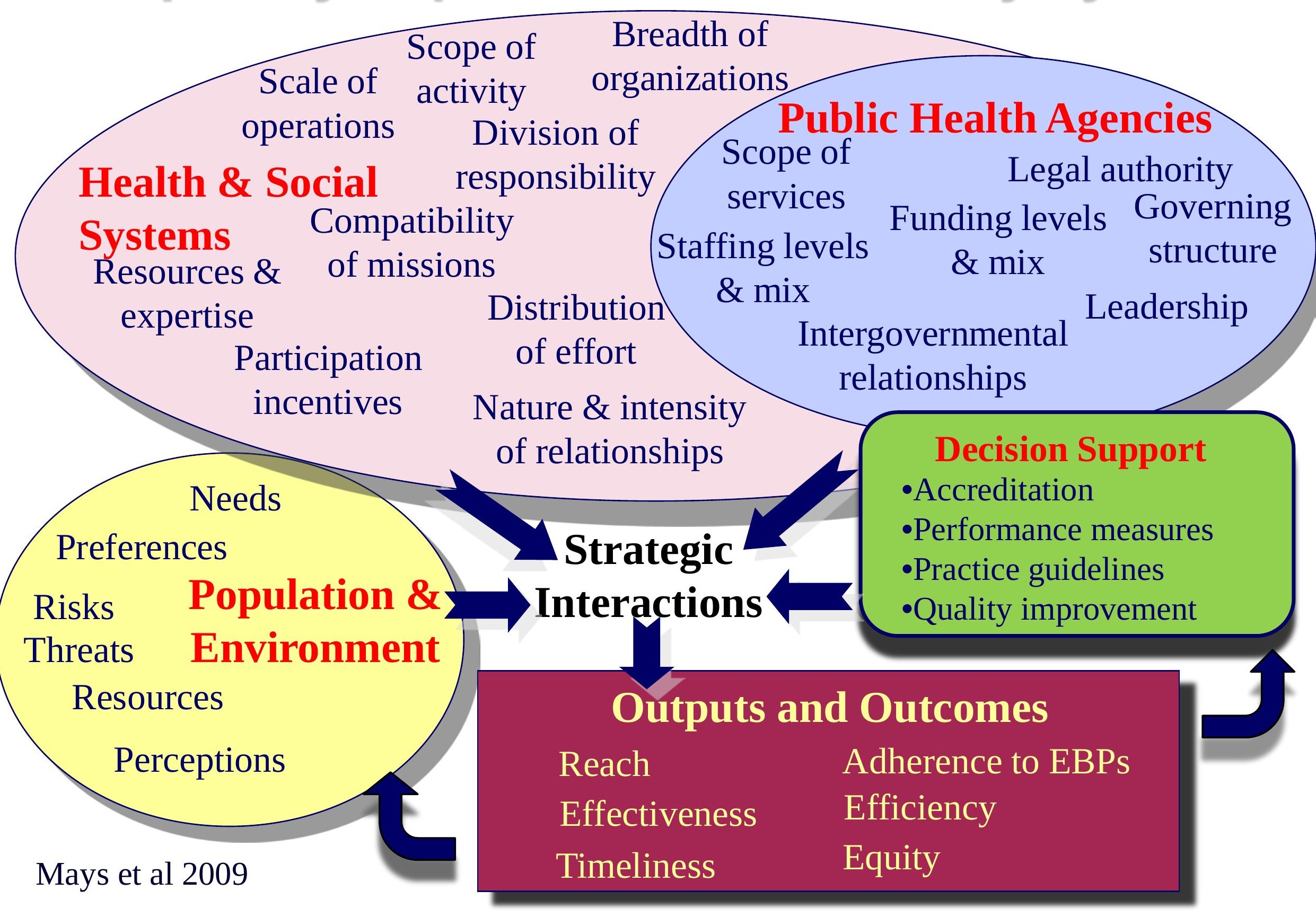




\section{Standardization vs. Customization in public health delivery systems}

Standardization

$\nabla$ Harmful variation

$\nabla$ Wasteful variation

$\nabla$ Inequitable variation

$\nabla$ Race to the bottom

$\triangle$ Network externalities: interoperability/coordination
Customization

$\Delta$ Target resources to greatest needs/risks

$\Delta$ Tailor approaches to values \& preferences of stakeholders

$\triangle$ Deploy unique resources \& skills to their best purposes

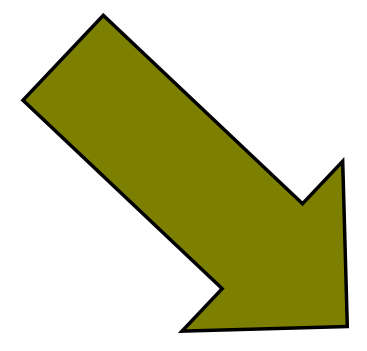

Effectiveness

Efficiency

Equity

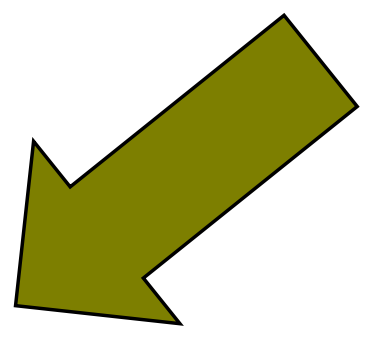




\section{Current delivery system shocks}

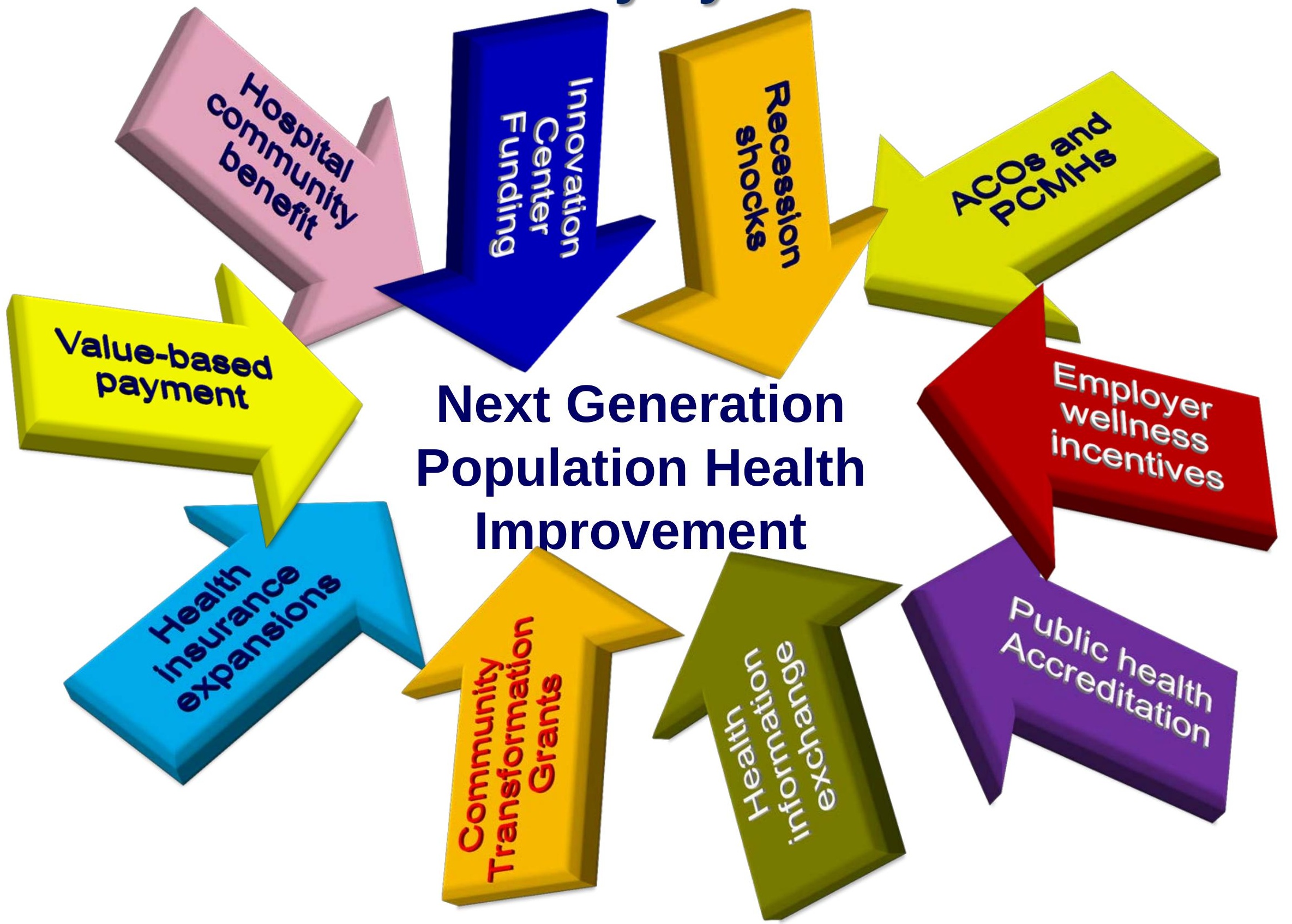




\section{PHSSR and policy relevance}

Subtitle D-Support for Prevention and Public Health Innovation

Patient Protection and Affordable Care Act of 2010

SEC. 4301. RESEARCH ON OPTIMIZING THE DELIVERY OF PUBLIC HEALTH SERVICES.

(a) IN GENERAL.-The Secretary of Health and Human Services (referred to in this section as the "Secretary"), acting through the Director of the Centers for Disease Control and Prevention, shall provide funding for research in the area of public health services and systems.

(b) REQUIREMENTS OF RESEARCH.-Research supported under this section shall include-

(1) examining evidence-based practices relating to prevention, with a particular focus on high priority areas as identified by the Secretary in the National Prevention Strategy or Healthy People 2020, and including comparing community-based public health interventions in terms of effectiveness and cost;

(2) analyzing the translation of interventions from academic settings to real world settings; and

(3) identifying effective strategies for organizing, financing, or delivering public health services in real world community settings, including comparing State and local health department structures and systems in terms of effectiveness and cost. 


\section{Learning how to succeed with population health strategies}

- Designed to achieve large-scale health improvement: neighborhood, city/county, region

- Target fundamental and often multiple determinants of health

v Mobilize the collective actions of multiple stakeholders in government \& private sector

- Usual and unusual suspects

- Infrastructure requirements

Mays GP. Governmental public health and the economics of adaptation to population health strategies. IOM Population Health Roundtable Discussion Paper. February 2014. 


\section{Overcoming collective action problems}

- Incentive compatibility $\rightarrow$ public goods

- Concentrated costs \& diffuse benefits

- Time lags: costs vs. improvements

- Uncertainties about what works

- Asymmetry in information

- Difficulties measuring progress

- Weak and variable institutions \& infrastructure

- Imbalance: resources vs. needs

- Stability \& sustainability of funding 


\section{Reform-relevant research: organization and structure}

- Who contributes to public health delivery?

n How are roles and responsibilities divided?

- How and why do delivery systems vary and change over time?

- How do system structures affect public health delivery and outcomes? 


\section{Data: public health production}

\section{National Longitudinal Survey of Public Health Systems}

v Cohort of 360 communities with at least 100,000 residents

च Followed over time: 1998, 2006, 2012, 2014*

v Measured from local public health official's perspective:

- Scope: availability of 20 recommended public health activities

- Network: types of organizations contributing to each activity

- Effort: contributed by designated local public health agency

- Quality: perceived effectiveness of each activity 


\section{Delivery of recommended public health activities in U.S. communities}

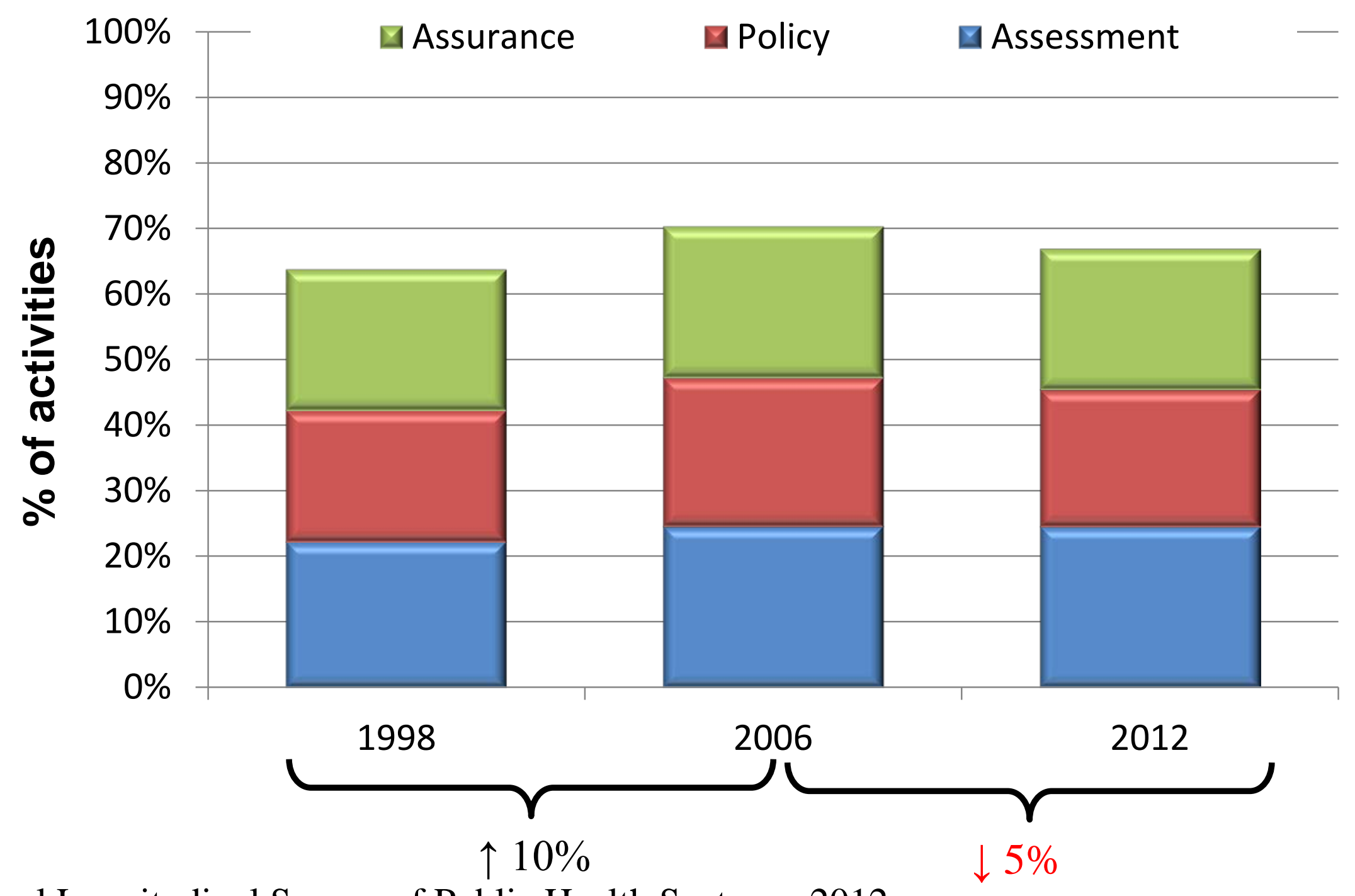

National Longitudinal Survey of Public Health Systems, 2012 


\section{Delivery of recommended public health activities in U.S. communities}

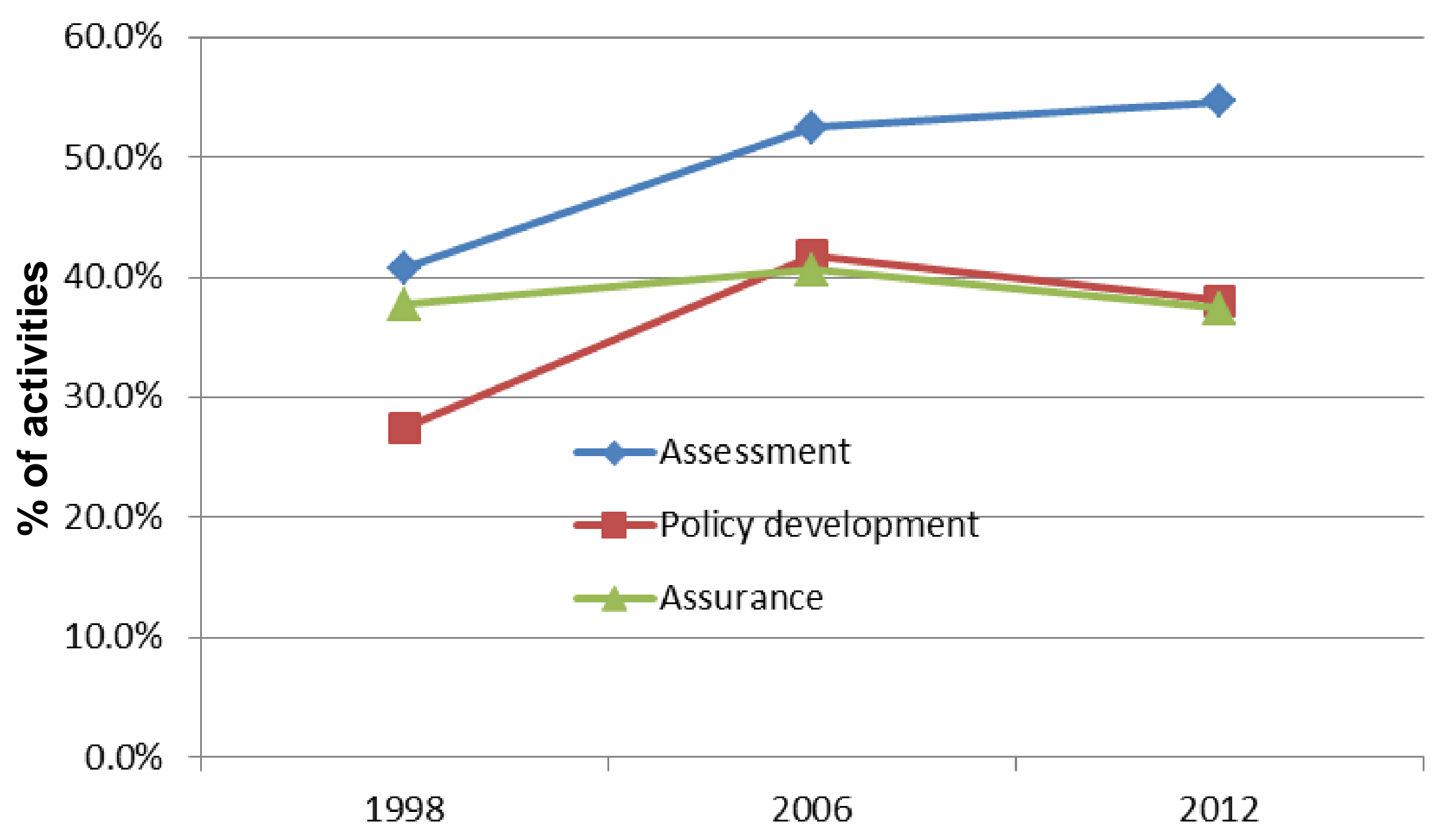

National Longitudinal Survey of Public Health Systems, 2012 


\section{Variation in Scope of Public Health Delivery}

Delivery of recommended public health activities, 2012

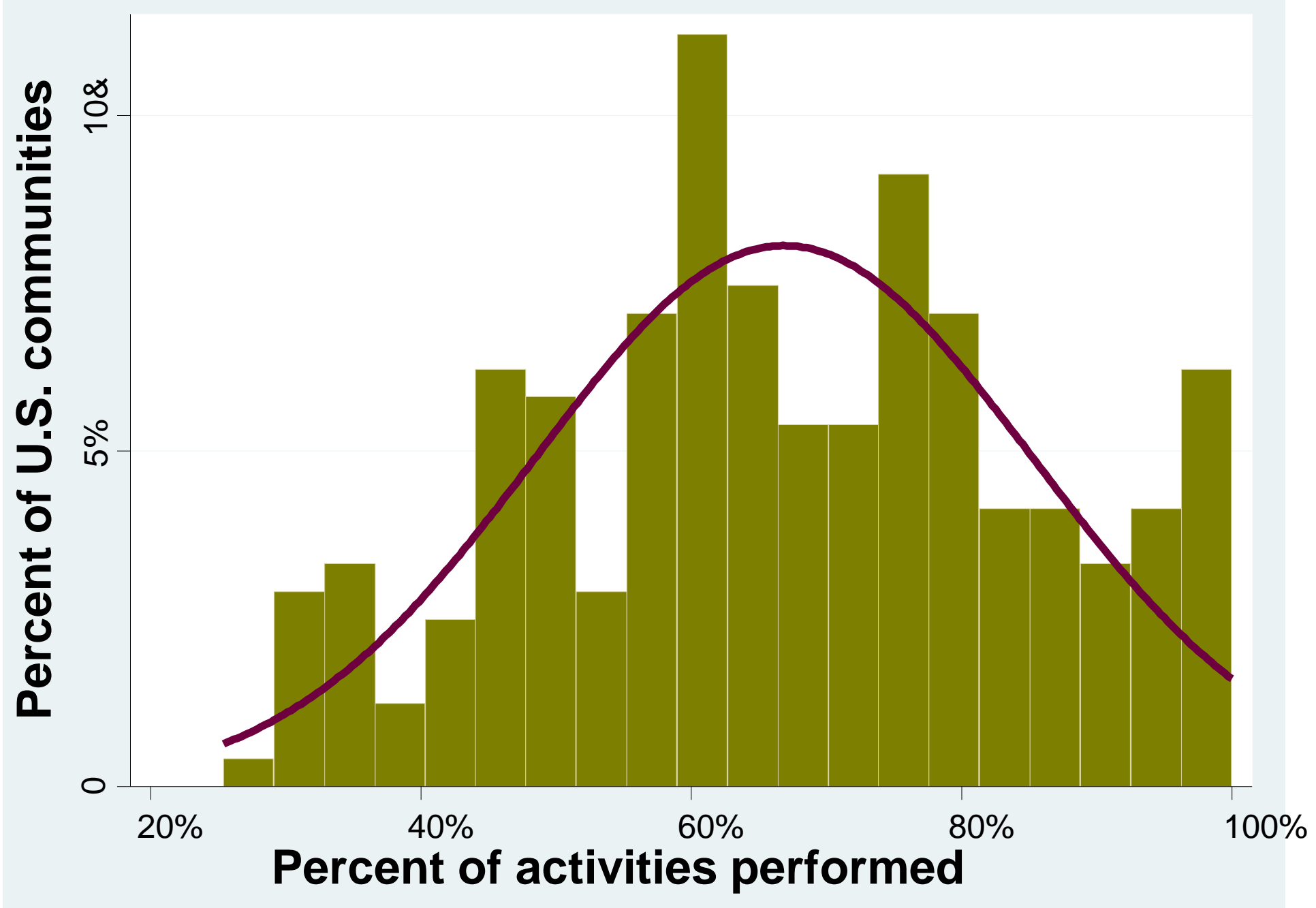

National Longitudinal Survey of Public Health Systems, 2012 


\section{Organizations contributing to local public health production}

\% Change 2006-2012 Scope of Production 2012

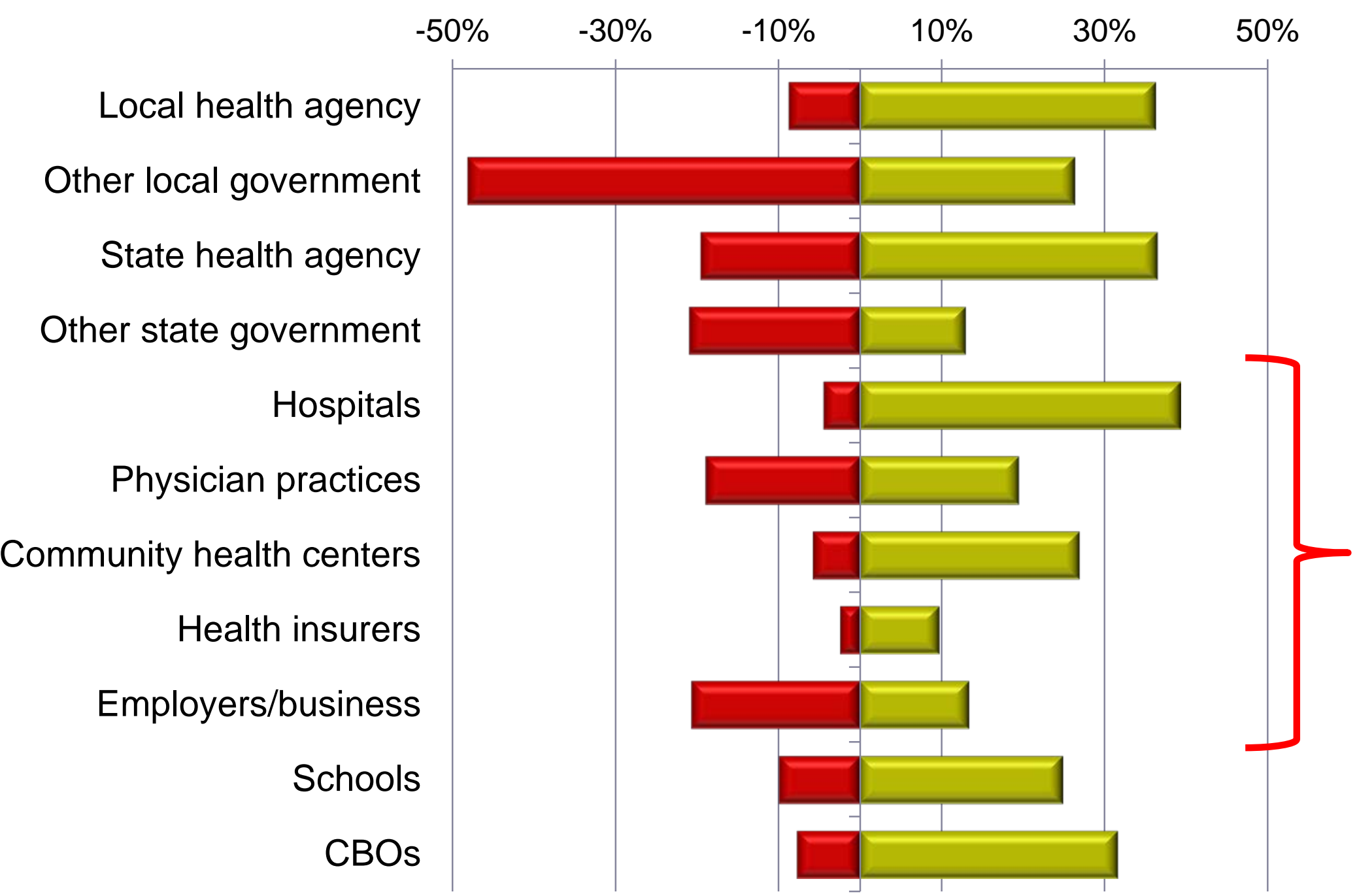

National Longitudinal Survey of Public Health Systems, 2012 


\section{Inter-organizational relationships in public health delivery systems}

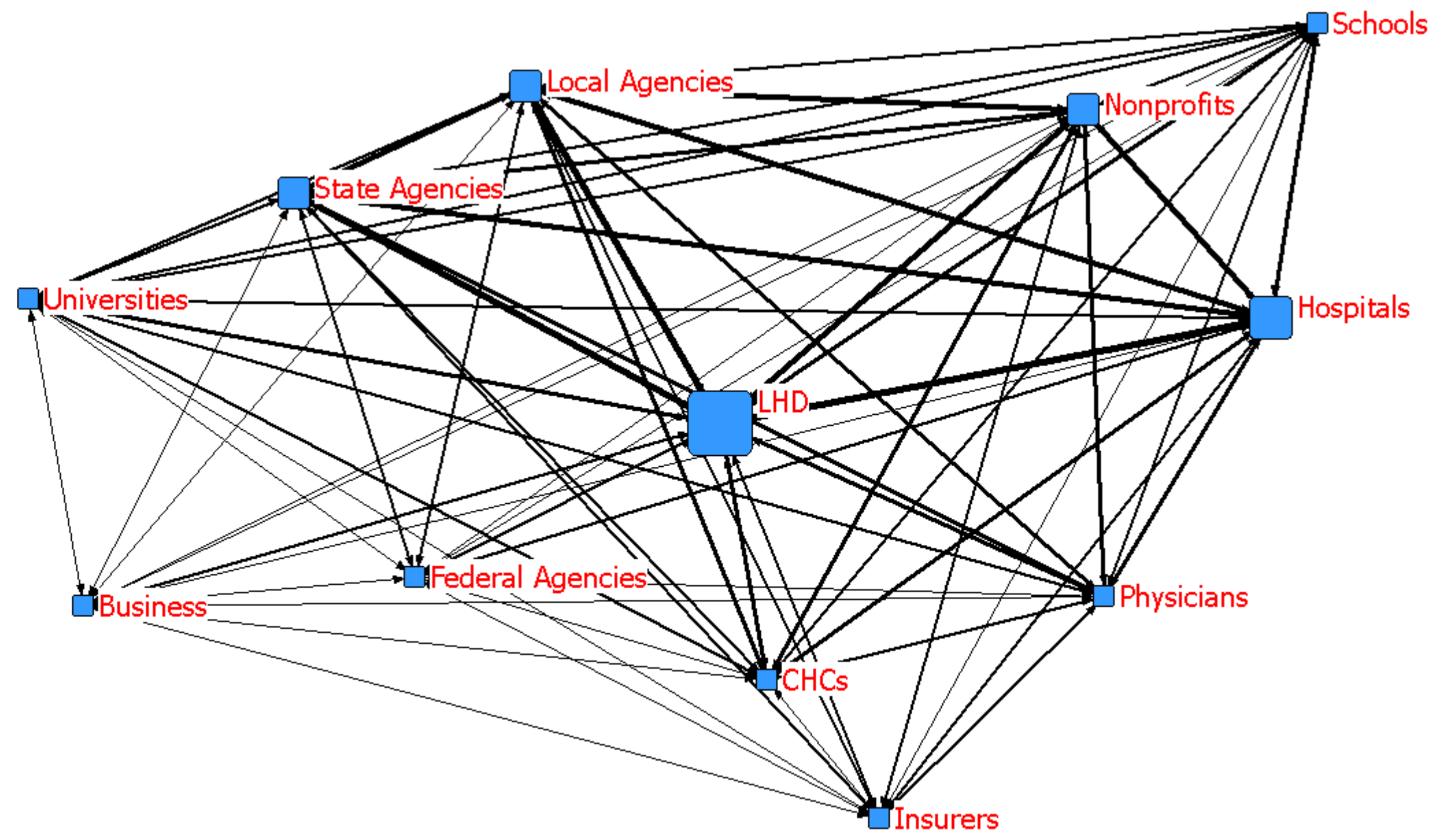

National Longitudinal Survey of Public Health Systems, 2012 


\section{Bridging capital in public health delivery systems Trends in betweenness centrality}

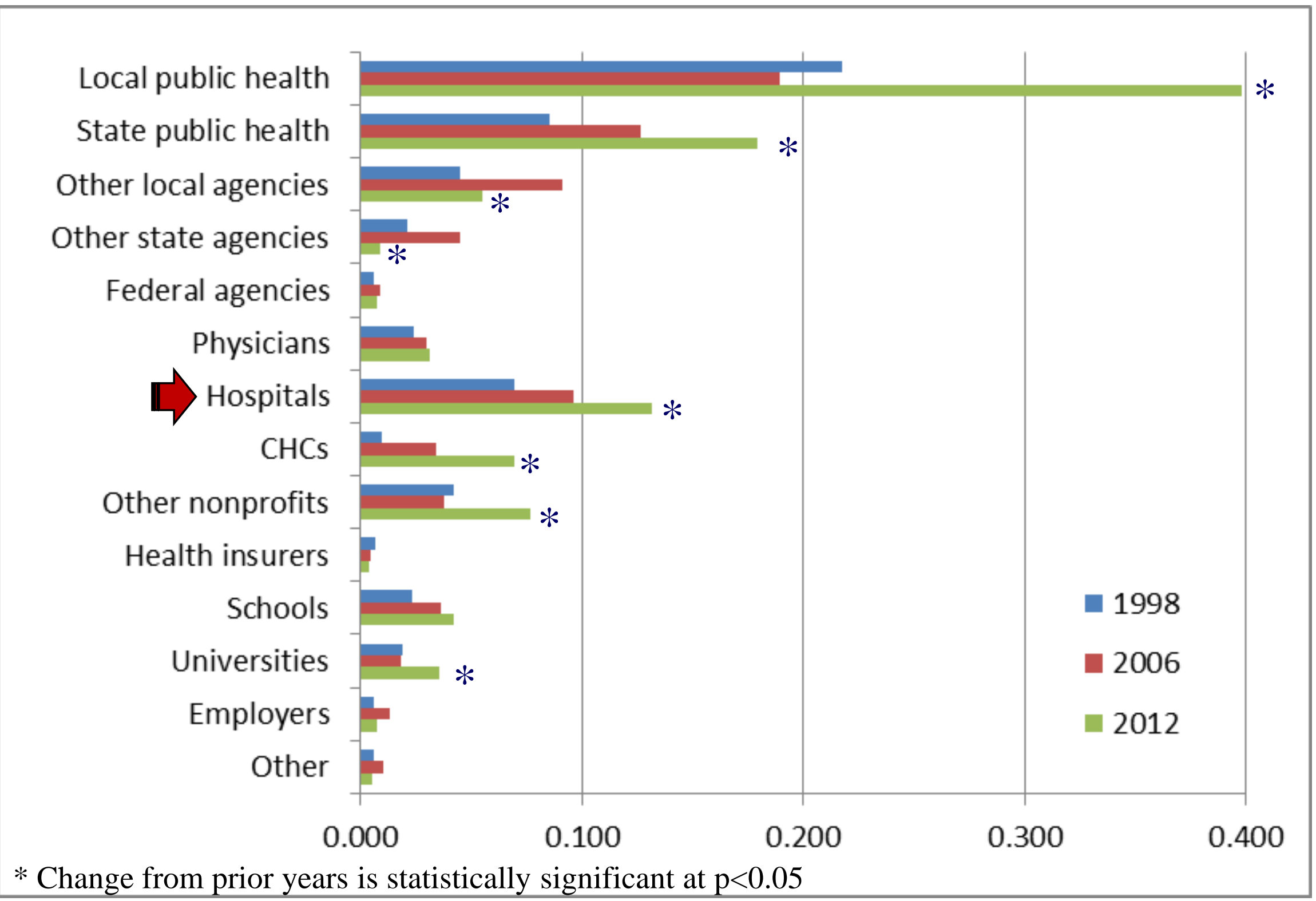




\section{Do other organizations complement or substitute for local public health agency effort? Results from Multivariate GLLAMM Models}

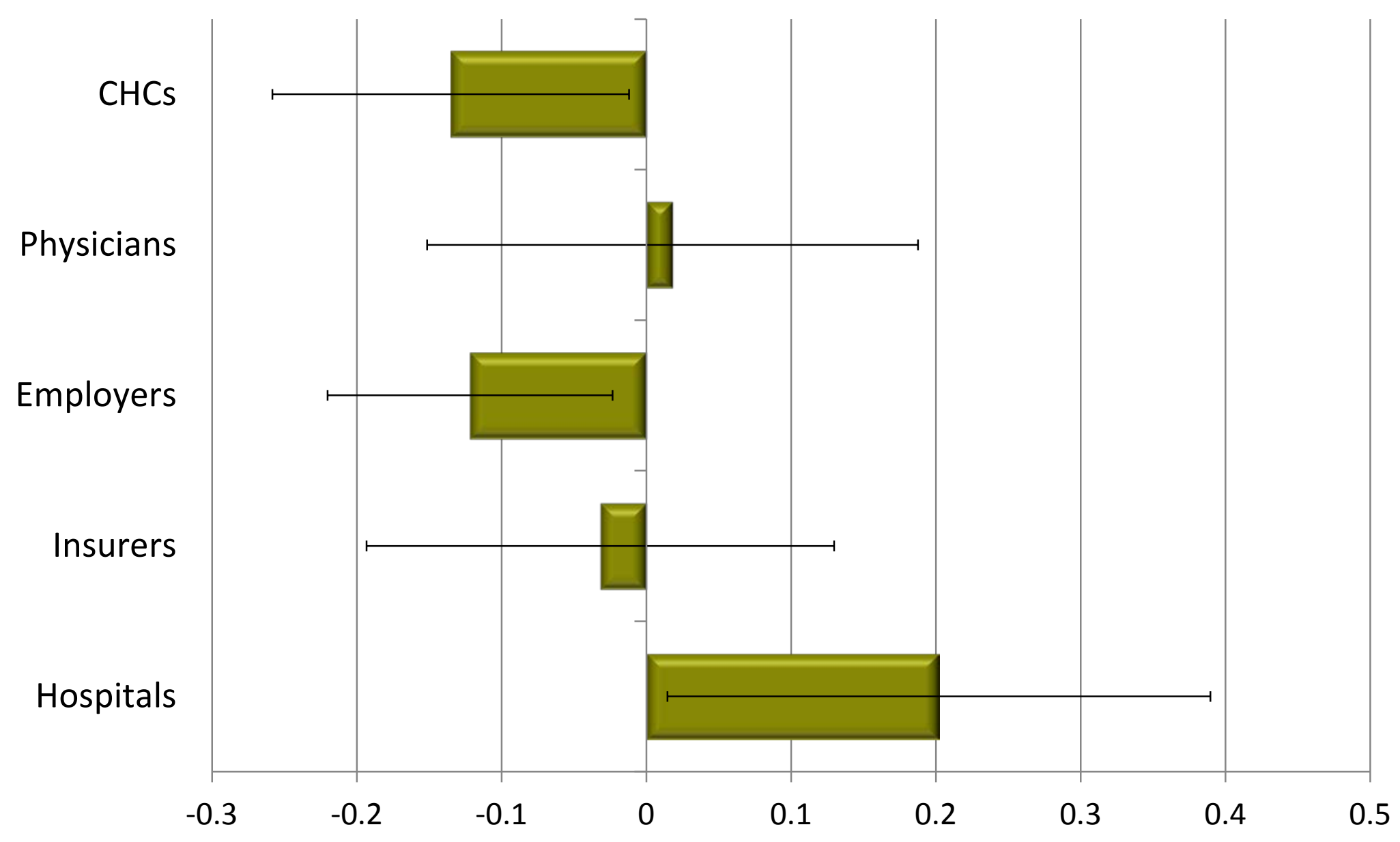

Note: GLLAMM estimates, holding all other variables constant in the model 
How do other organizations affect the total supply of public health activities?

Results from Multivariate GLLAMM Models

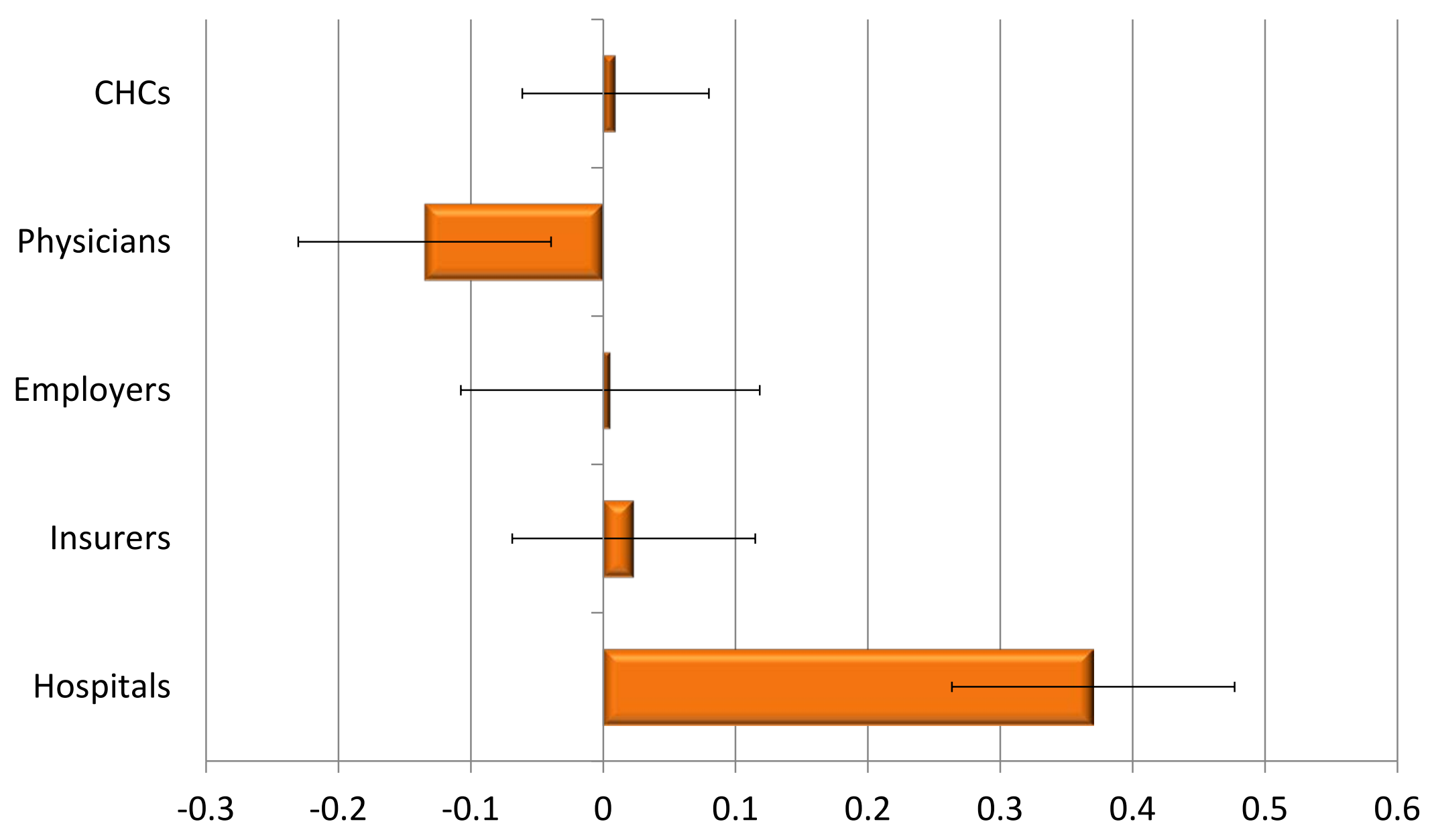

Note: GLLAMM estimates, holding all other variables constant in the model 


\section{Estimated crowd-out in hospital contributions to public health activities}

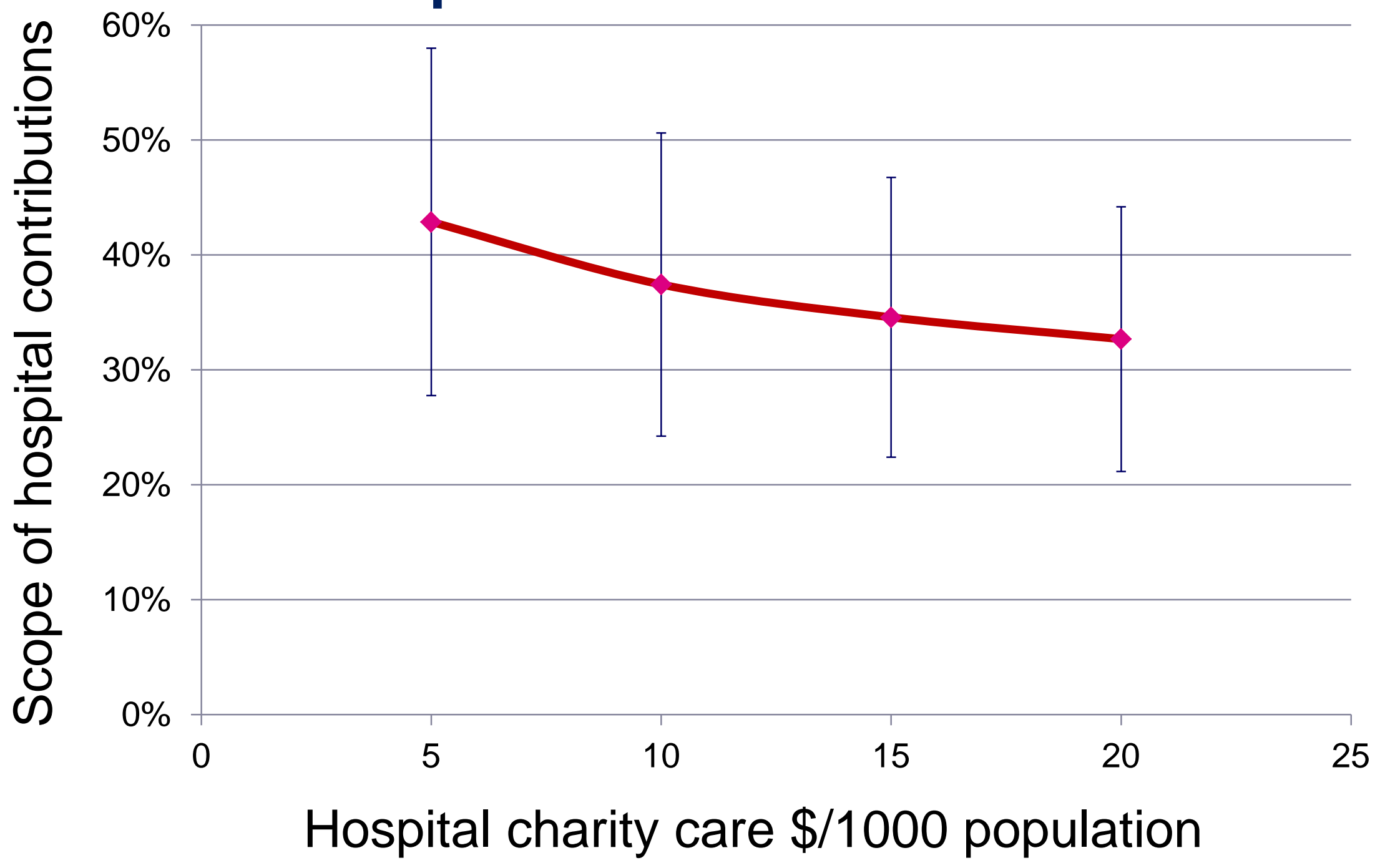

Note: GLLAMM estimates, holding all other variables constant in the model 


\section{A typology of public health delivery systems}

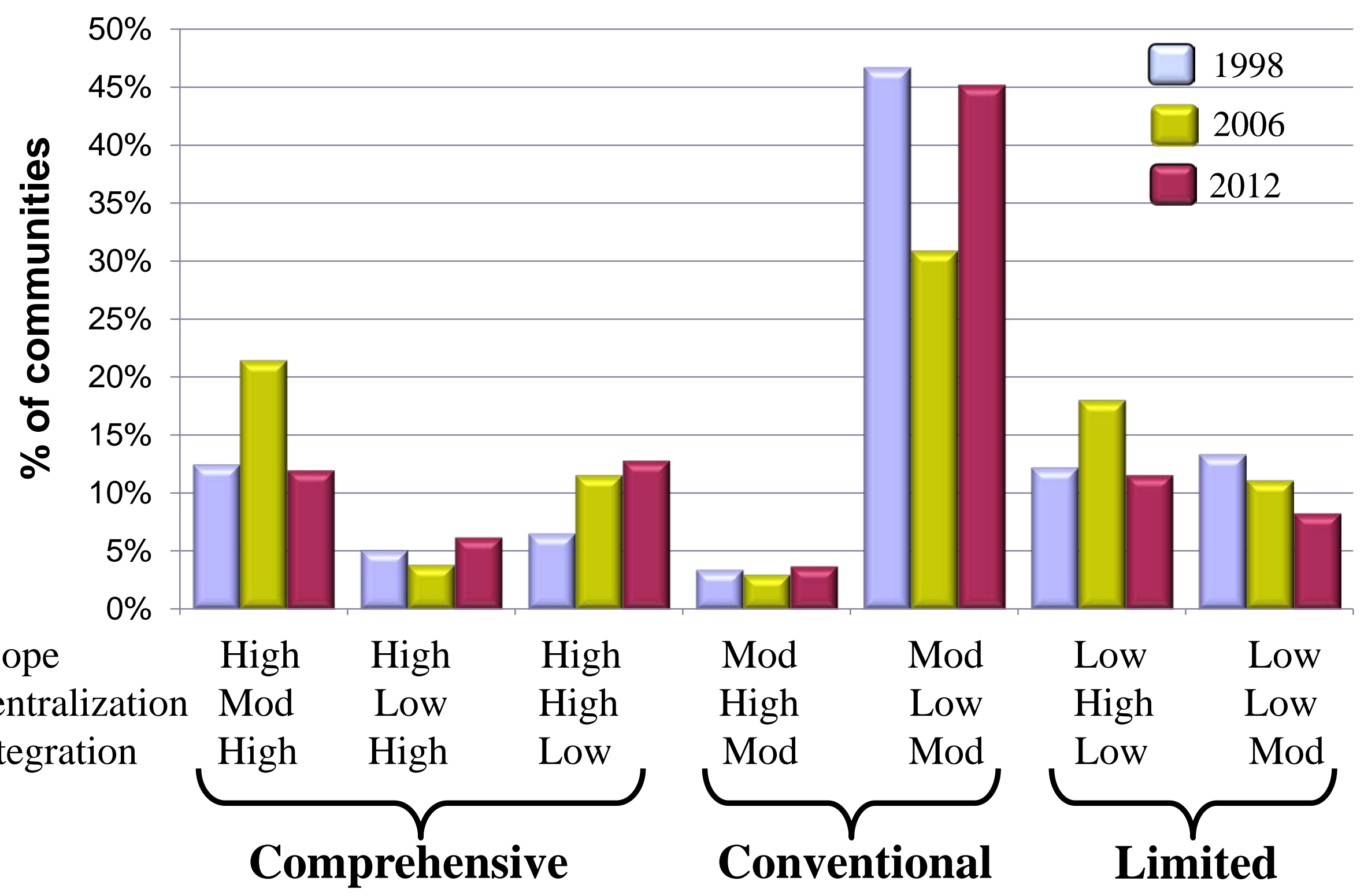

Source: Mays et al. 2010; 2012 


\section{Population health and delivery system change}

Percent Changes in Preventable Mortality Rates Attributable to Delivery System Type
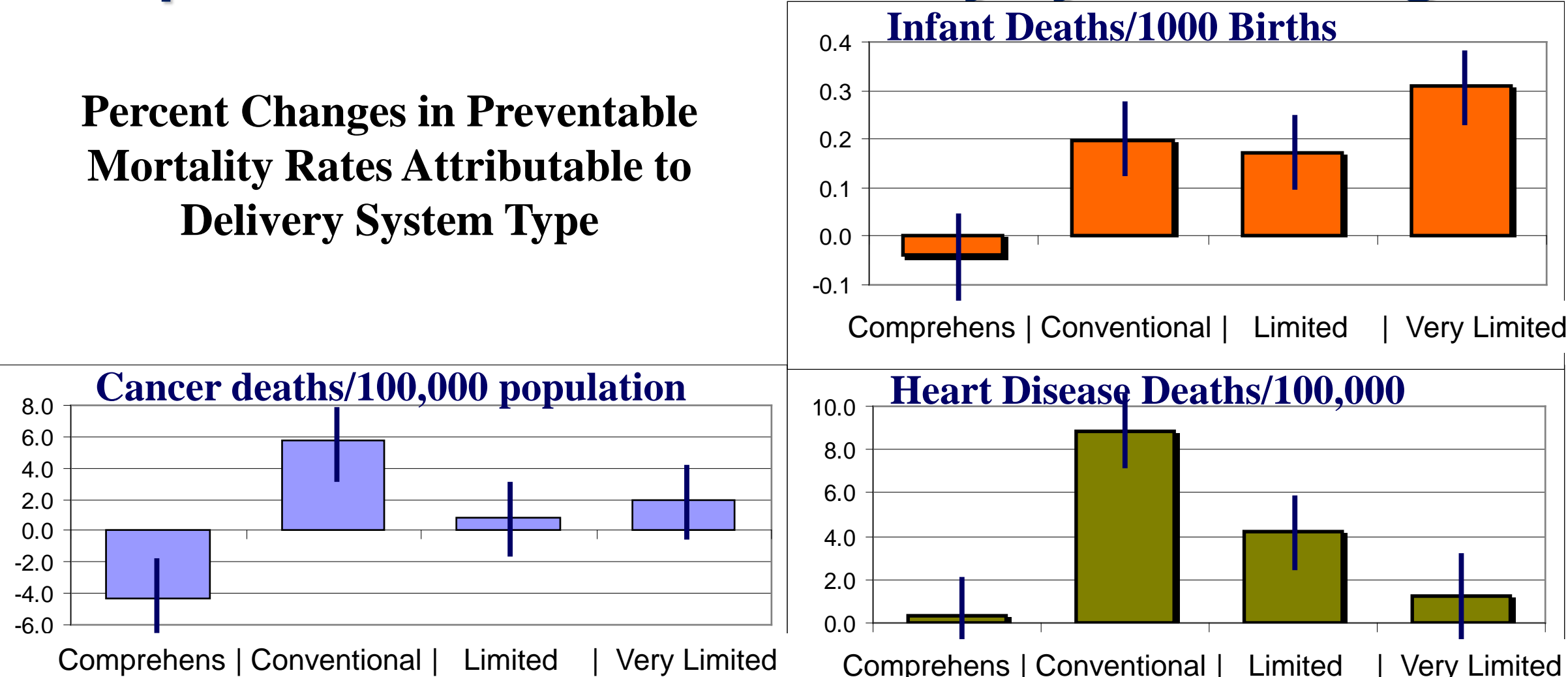

Comprehens | Conventional | Limited | Very Limited

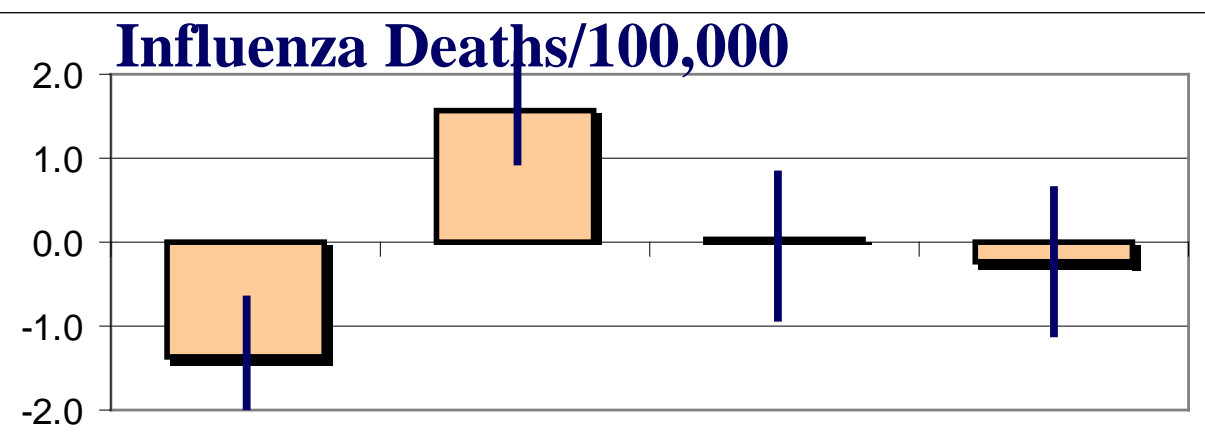

Comprehens | Conventional | Limited | Very Limited

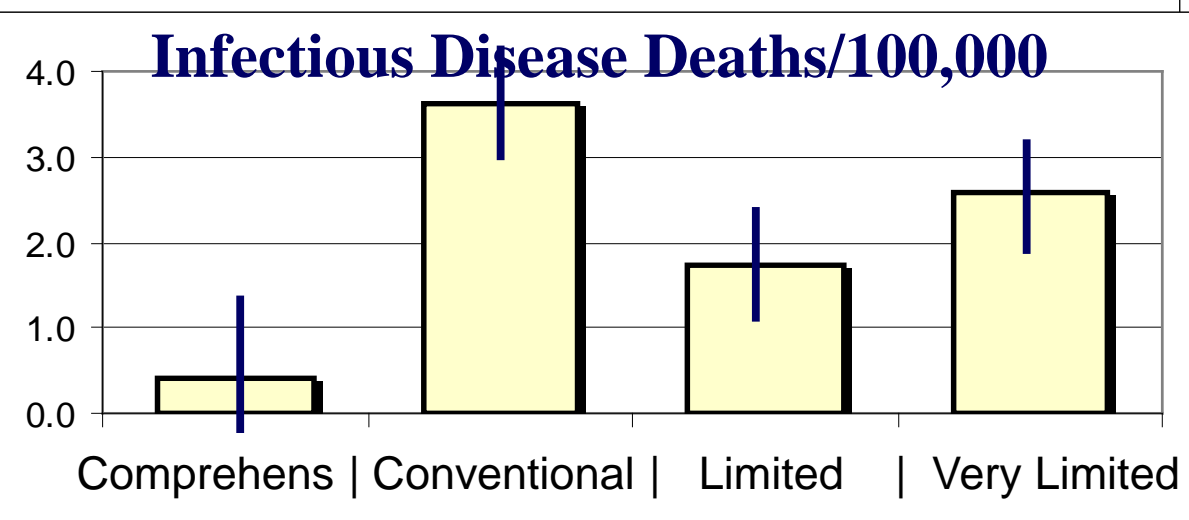

Fixed-effects models control for population size, density, age composition, poverty status, racial composition, and physician supply 


\section{Reform-relevant research: finance and economics}

- How does public health spending vary across communities and change over time?

- What are the health effects attributable to changes in public health spending?

- What are the medical cost effects attributable to changes in public health spending?

- What are the opportunities for improving efficiency in public health delivery? 


\section{What we know, sort of...}

Governmental Expenditures for Public Health Activity, USDHHS National Health Expenditure Accounts

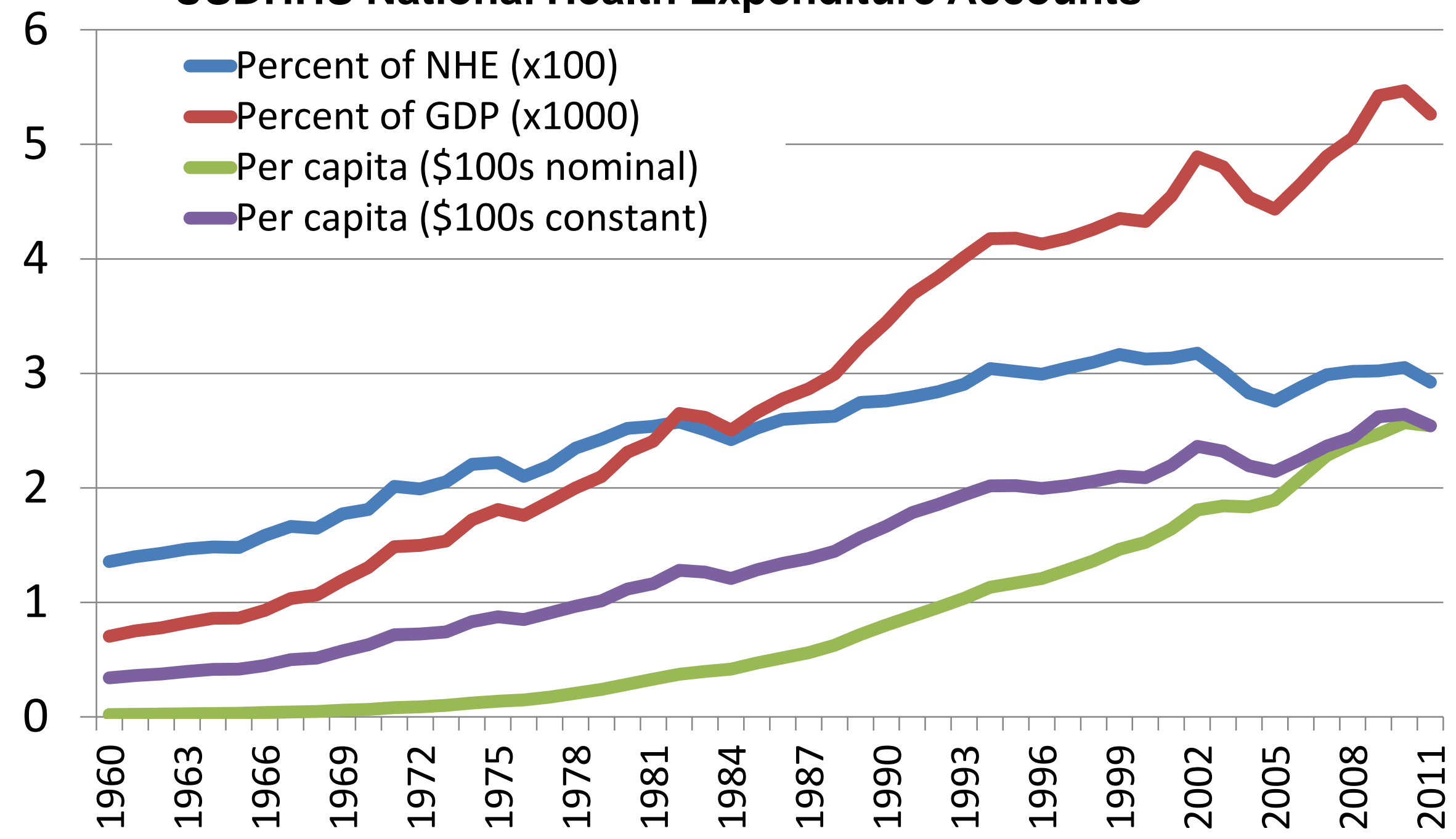

U.S. Centers for Medicare and Medicaid Services, Office of the Chief Actuary 


\section{Variation in Local Public Health Spending}

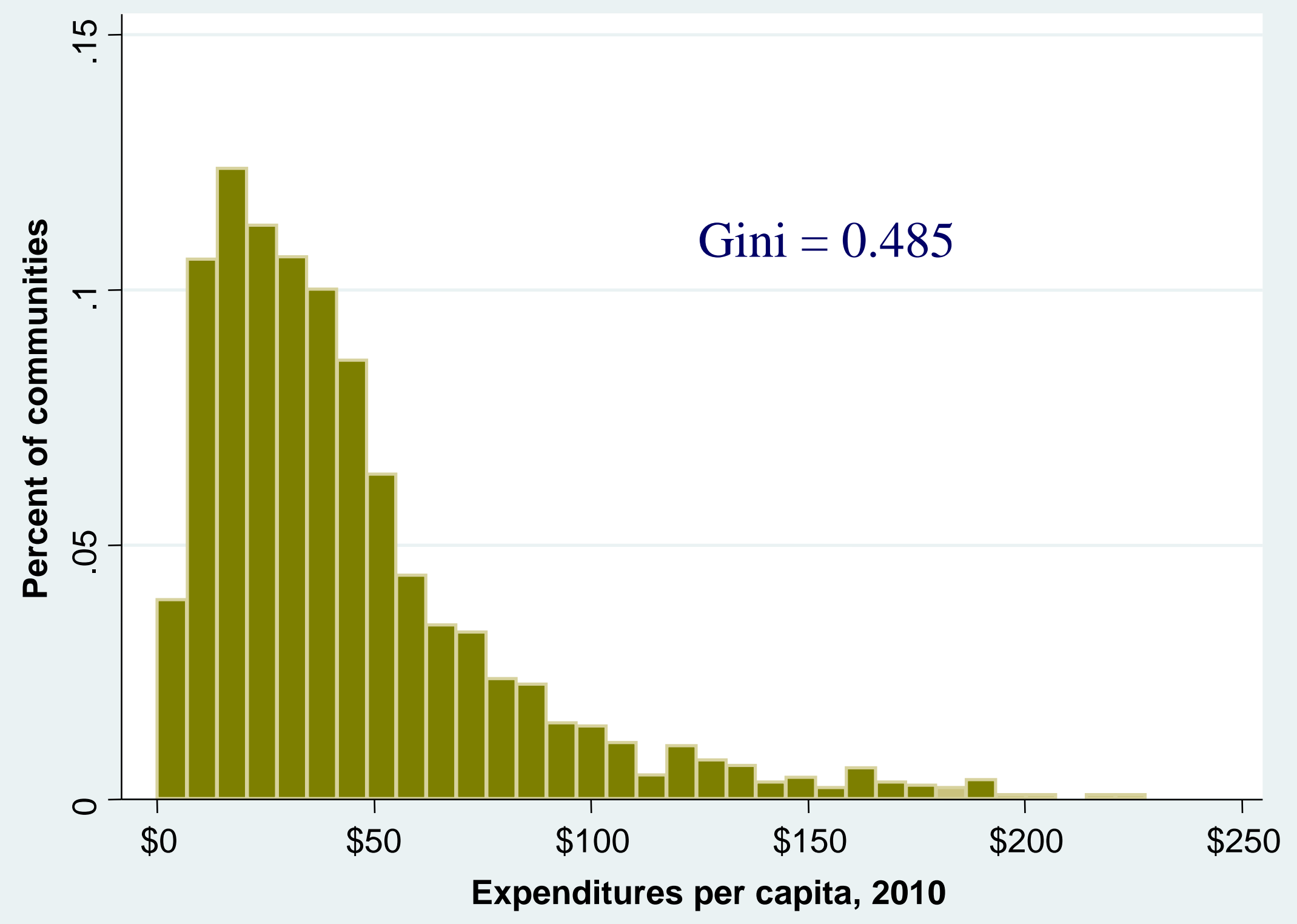




\section{Changes in Local Public Health Spending 1993-2010}

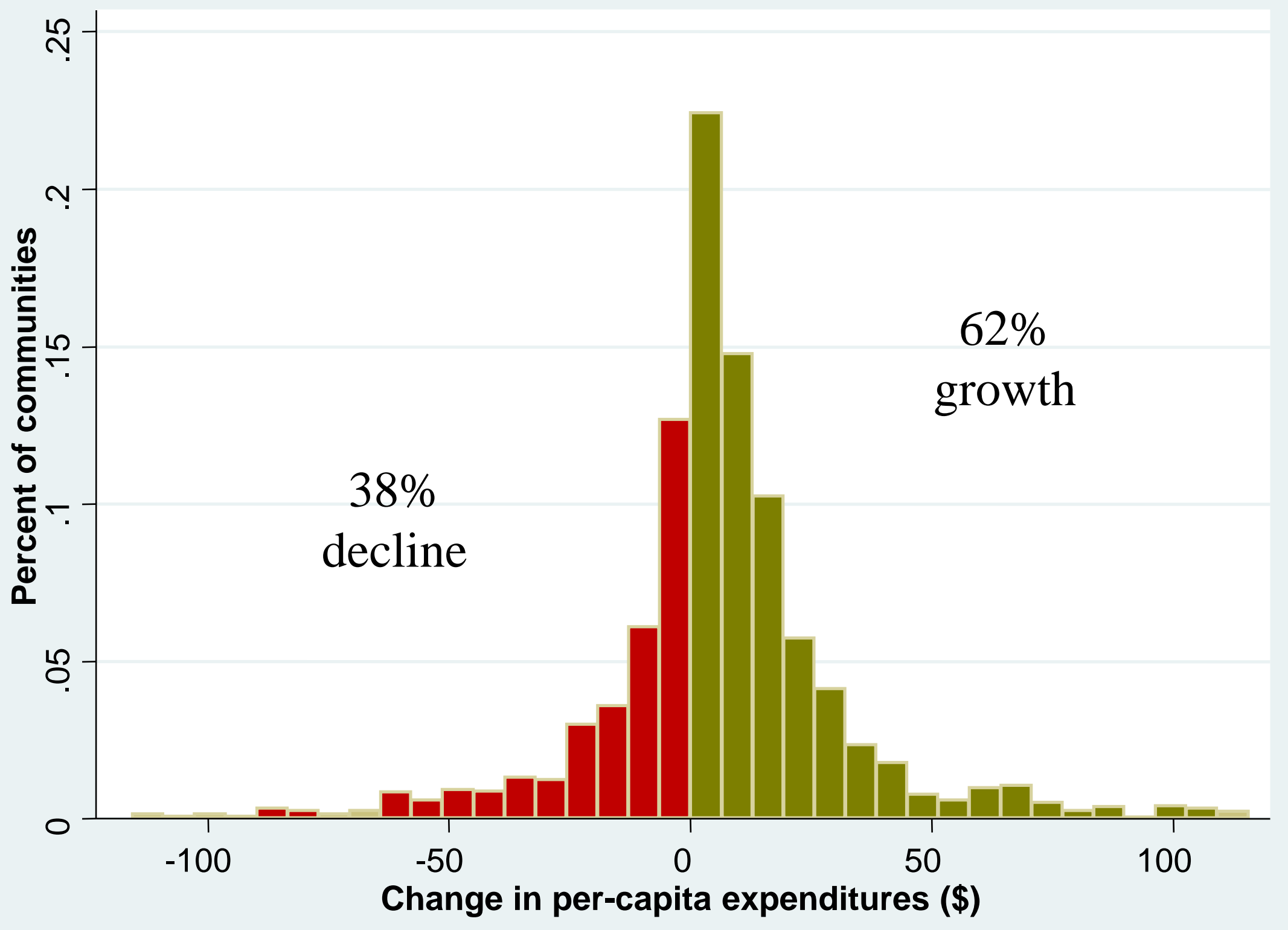




\section{Determinants of Local Public Health Spending Levels}

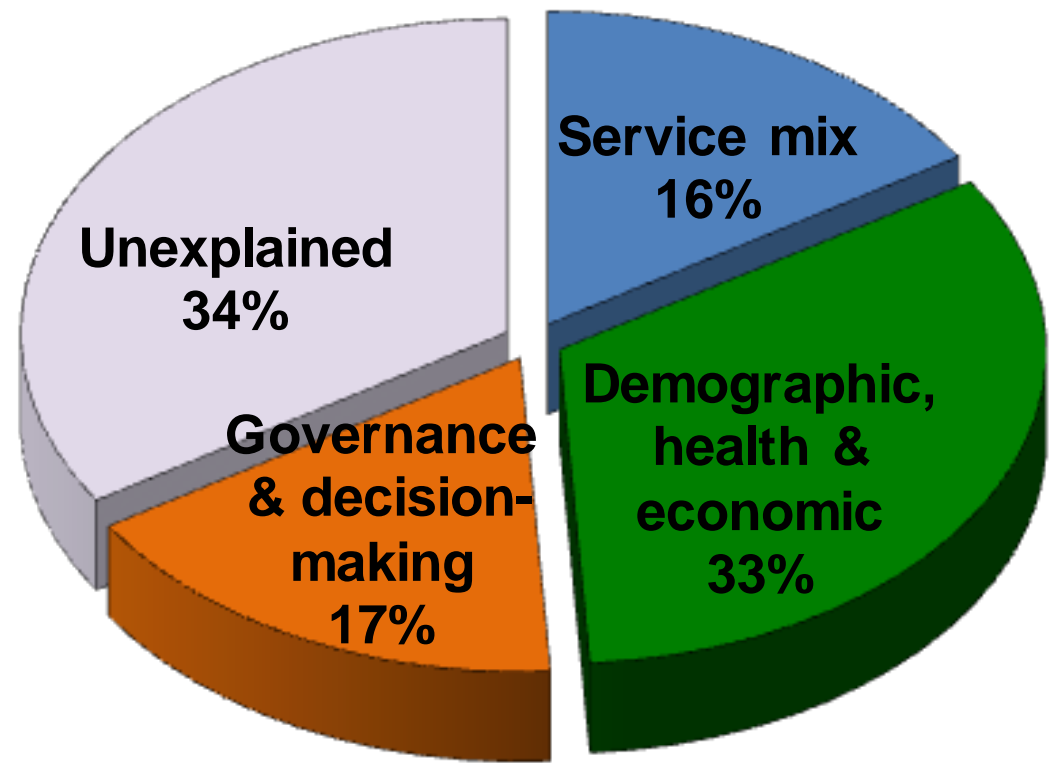

- Delivery system size \& structure

- Service mix

- Population needs and risks

- Efficiency \& uncertainty 


\section{Medical cost offsets attributable to investments in public health delivery, 1993-2008}

For every $\$ 10$ of public health spending, $\approx \$ 9$ are recovered in lower medical care spending over 15 years

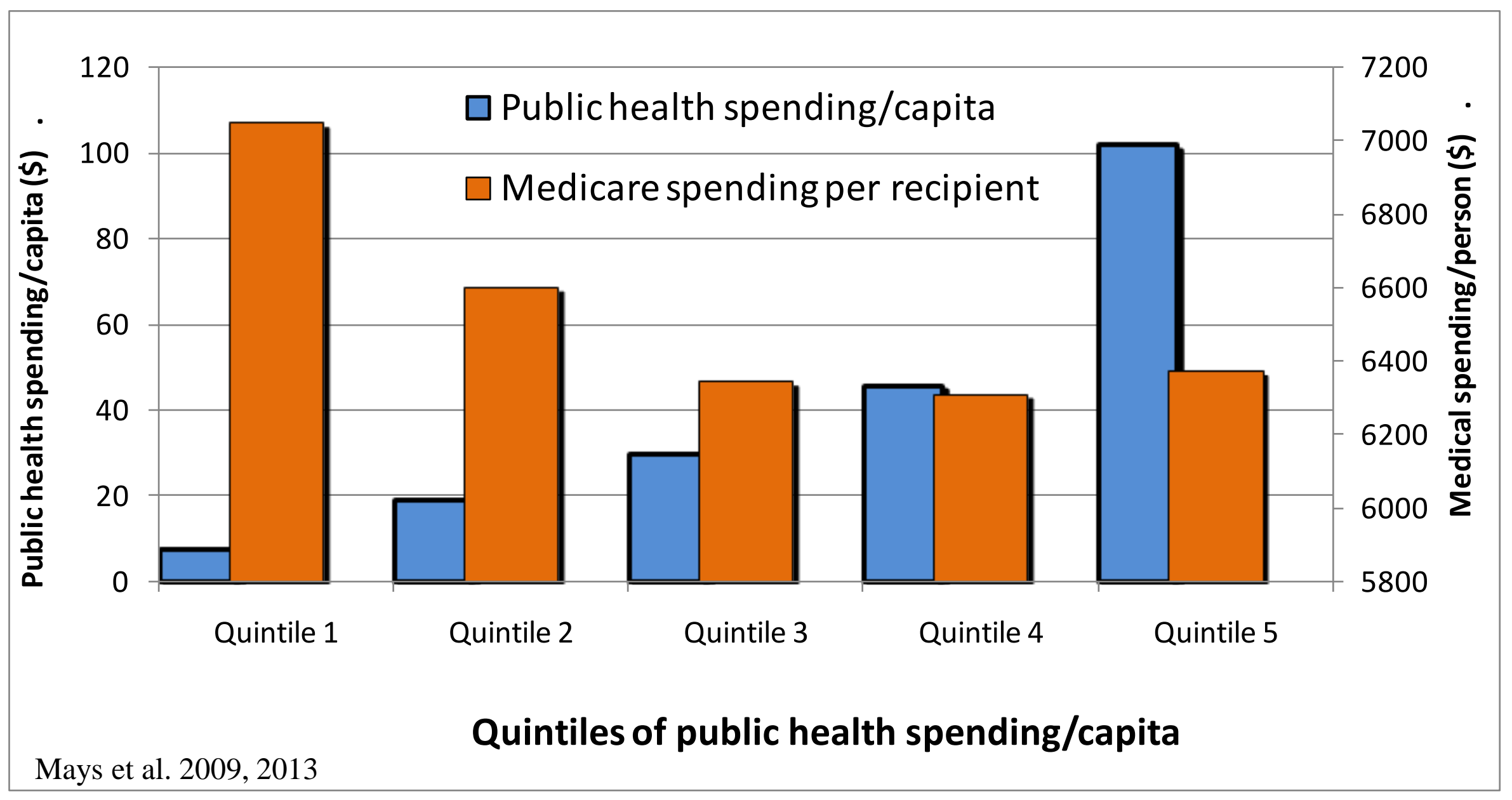




\section{Community-specific estimates of public health spending on heart disease mortality}

Impact of $10 \%$ Increase in Public Health Spending/Capita Based on Income Per Capita in Communities
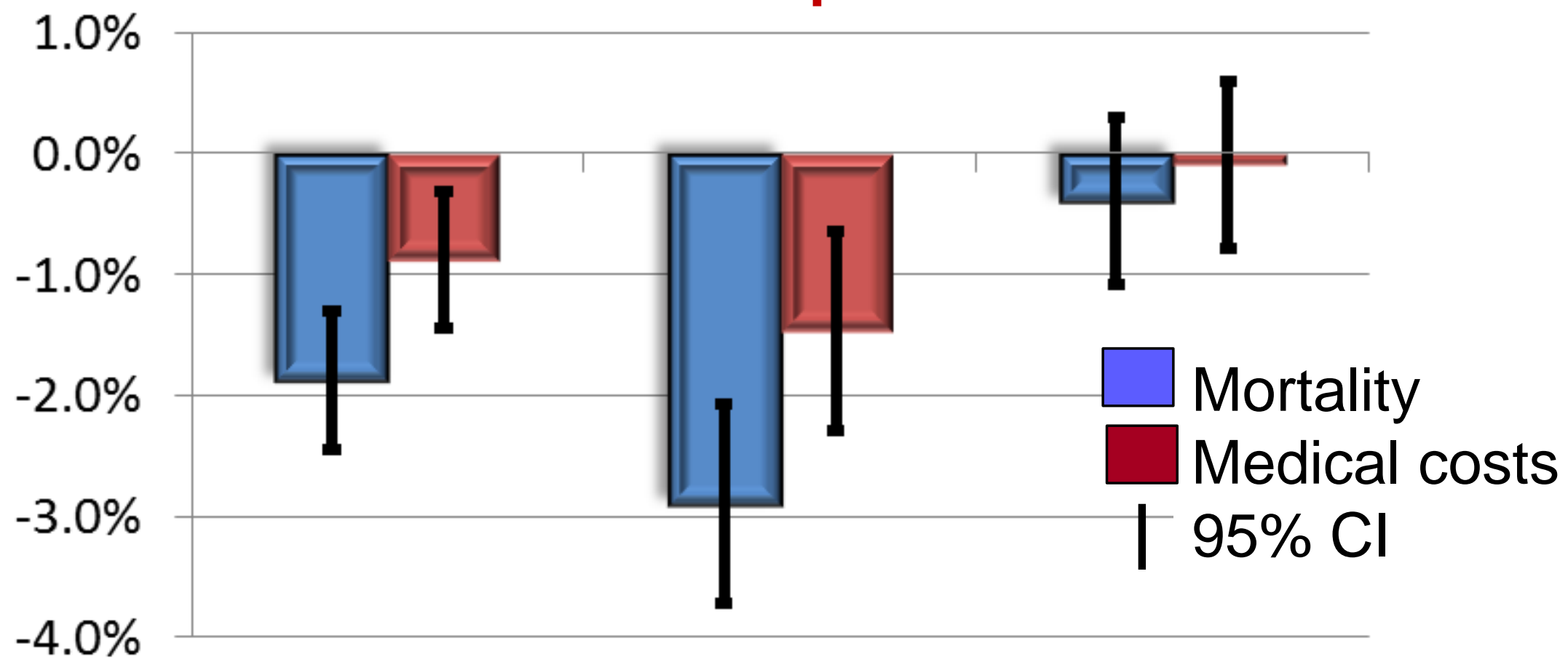

Average all Bottom $20 \%$ of Top $20 \%$ of communities communities communities 


\section{Community-specific estimates of public health spending on heart disease mortality}

Impact of $10 \%$ Increase in Public Health Spending/Capita Based on Scope of Public Health Services Delivered

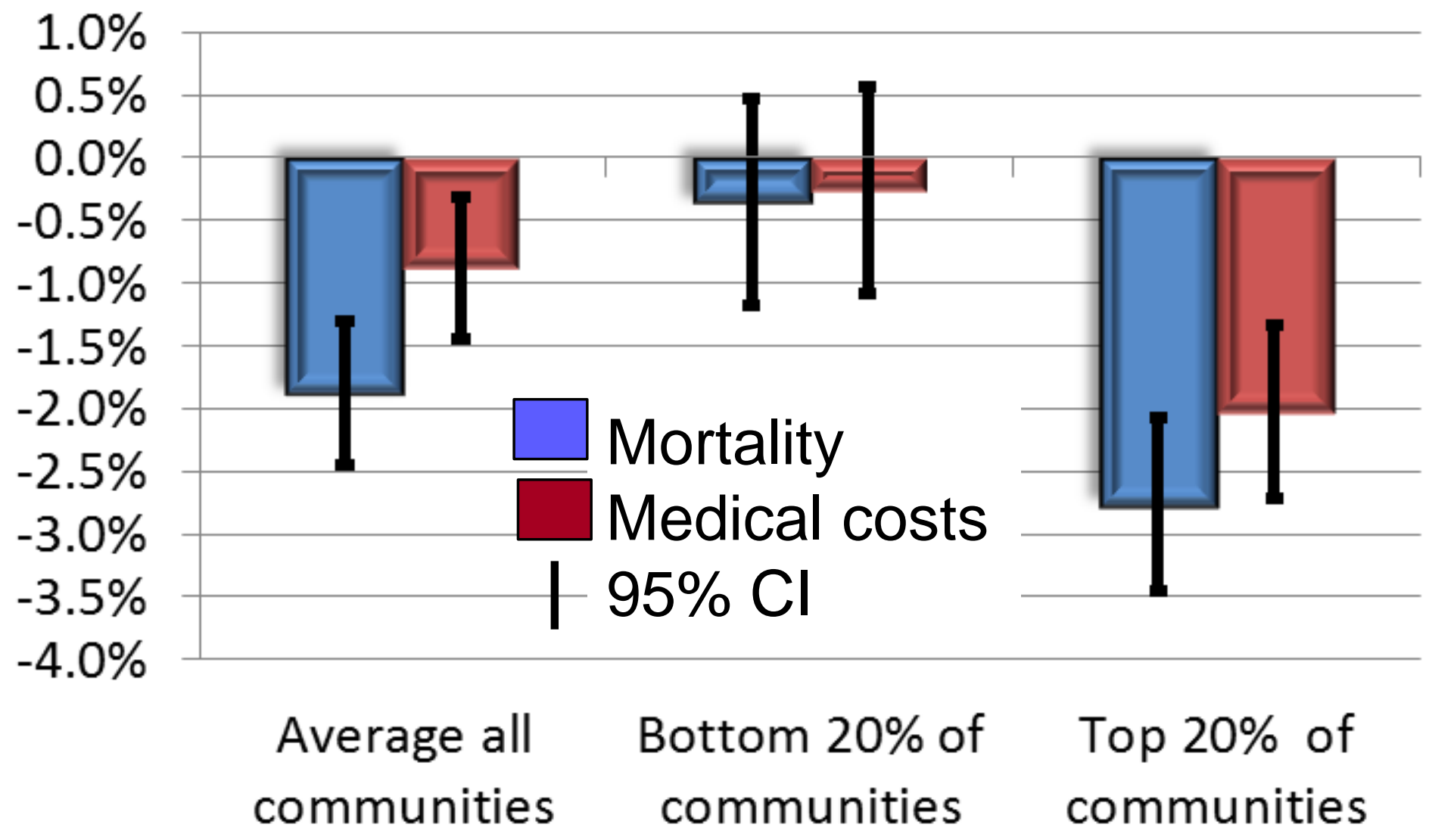

Log IV regression estimates controlling for community-level and state-level characteristics

Mays et al. forthcoming 2014 


\section{How long does it take:}

Cumulative effects of public health spending

Changes in Mortality and Medical Care Spending Attributable to $10 \%$ Increase in Public Health Spending /Capita

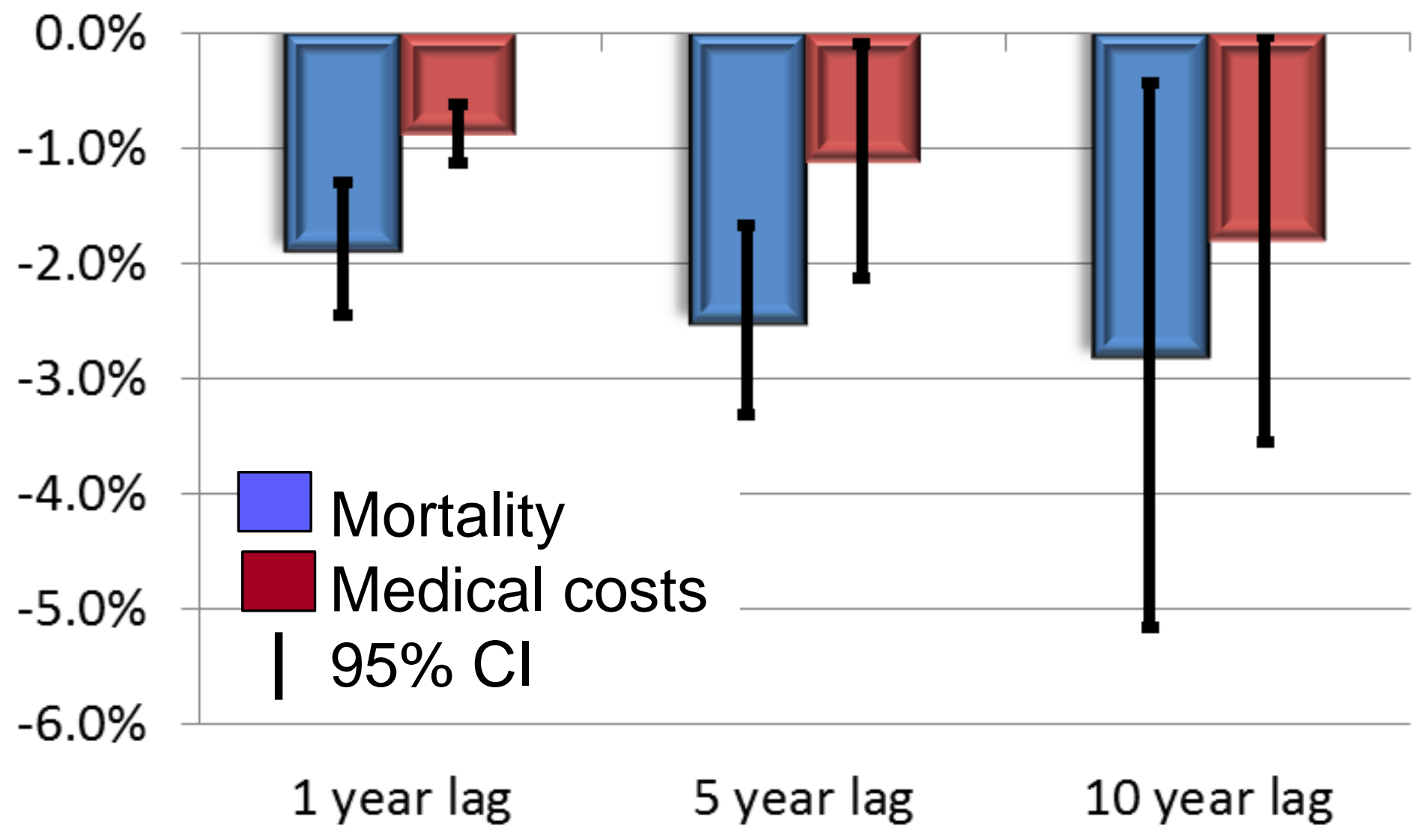

Log IV regression estimates controlling for community-level and state-level characteristics

Mays et al. forthcoming 2014 


\section{Economies of scale and scope in public health delivery systems}

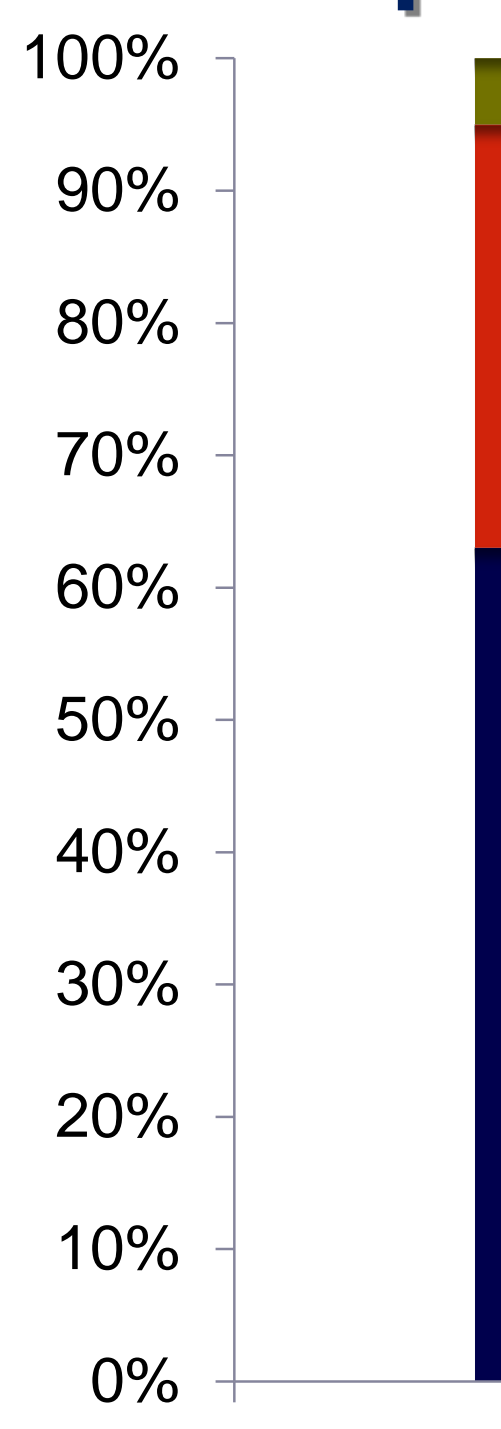

Jurisdiction Size

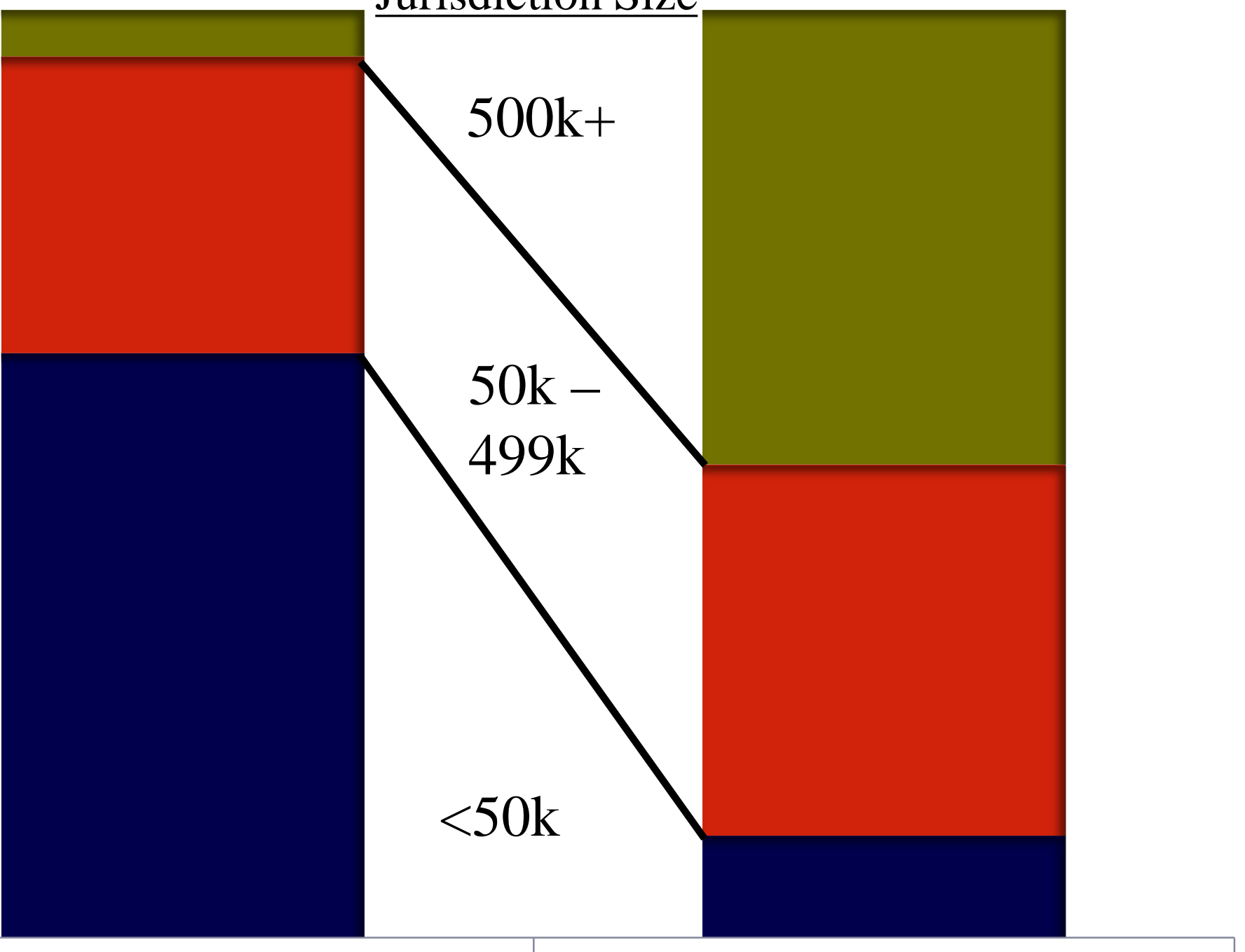

$\%$ of Agencies

$\%$ of Population Served

Source: 2010 NACCHO National Profile of Local Health Departments Survey 


\section{Empirical estimates of scale and scope economies}

Scale (Population in 1000s) Quality (Perceived Effectiveness)

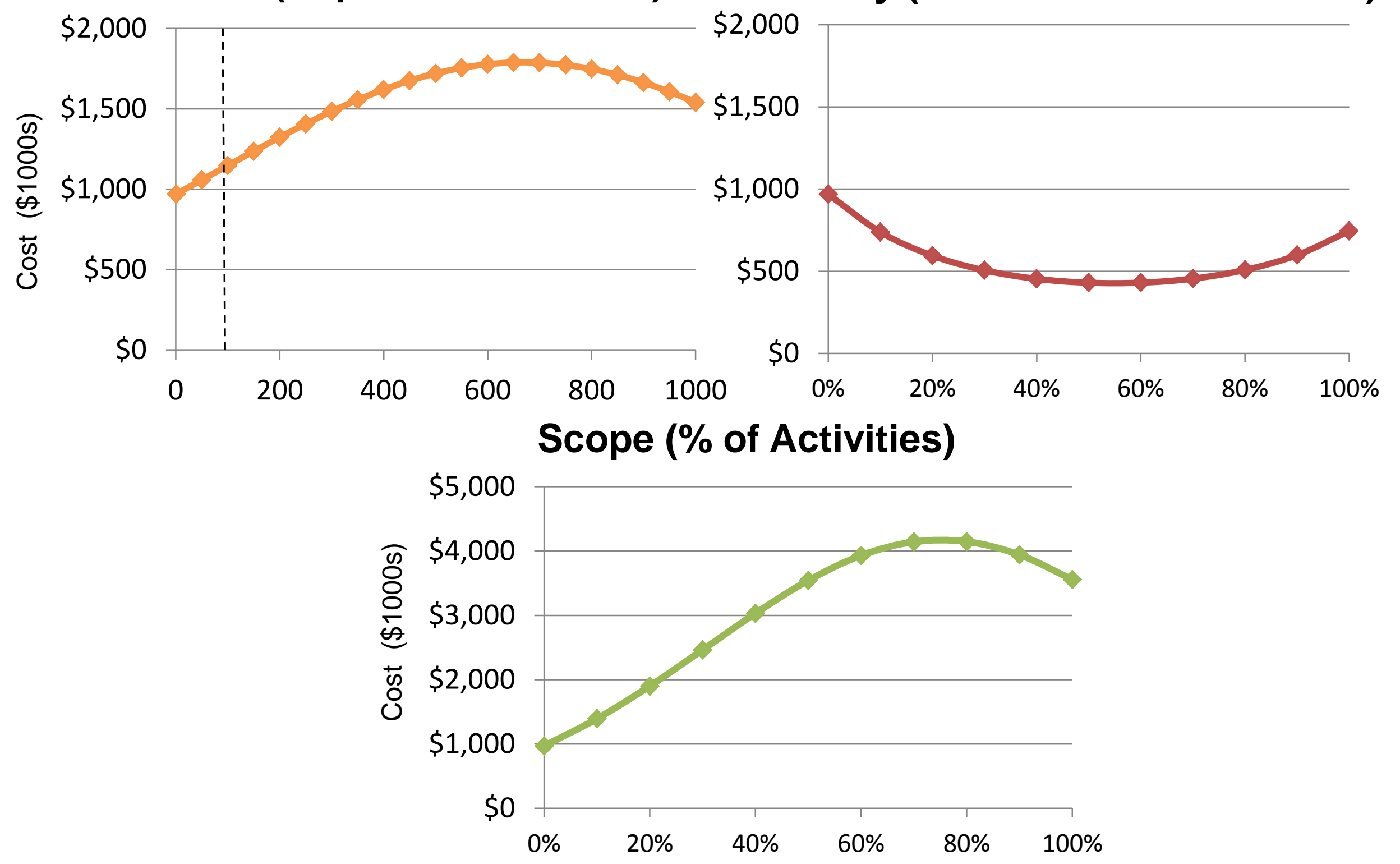




\section{Simulated Effects of Regionalization}

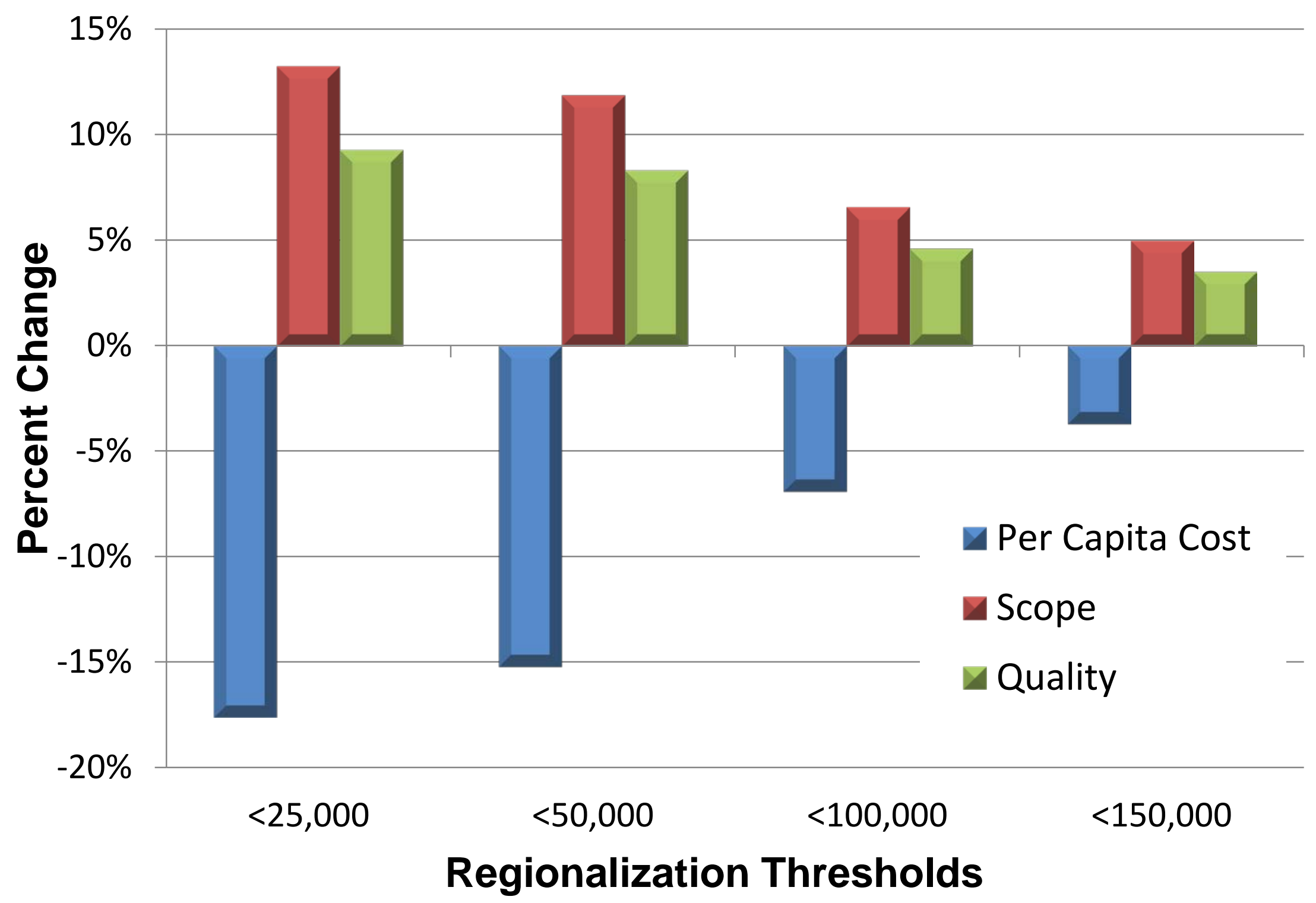




\section{Pathways for research and learning about public health value}

- Measuring practice \& performance

- Detecting variation in practice

- Examining determinants of variation

- Organization

- Financing

- Workforce

- Determining consequences of variation

- Health outcomes - Medical care use

- Economic outcomes - Disparities

- Testing strategies to reduce harmful, wasteful, \& inequitable variation in practice and outcomes
Descriptive

Inferential

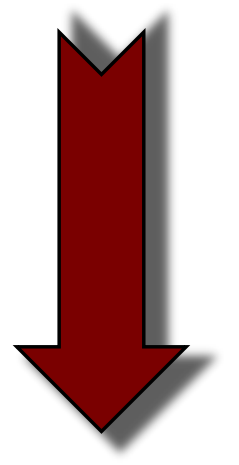

Translational 


\section{PBRNs and Research Translation}

\section{Local Health Departments Engaged in Research Implementation \& Translation Activities During Past 12 months}

\begin{tabular}{|c|c|c|c|}
\hline Activity & $\begin{array}{l}\text { PBRN Agencies } \\
\text { Percent/Mean }\end{array}$ & $\begin{array}{l}\text { National Sample } \\
\text { Percent/Mean }\end{array}$ & \\
\hline Identifying research topics & $94.1 \%$ & $27.5 \%$ & 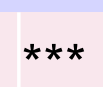 \\
\hline Planning/designing studies & $81.6 \%$ & $15.8 \%$ & *** \\
\hline Recruitment, data collection \& analysis & $79.6 \%$ & $50.3 \%$ & $\star \star$ \\
\hline Disseminating study results & $84.5 \%$ & $36.6 \%$ & ** \\
\hline Applying findings in own organization & $87.4 \%$ & $32.1 \%$ & ** \\
\hline Helping others apply findings & $76.5 \%$ & $18.0 \%$ & $\star \star \star *$ \\
\hline Research implementation composite & $84.04(27.38)$ & $30.20(31.38)$ & ** \\
\hline $\mathrm{N}$ & 209 & 505 & \\
\hline
\end{tabular}

Mays et al. American Journal of Preventive Medicine 2013. 


\section{Diffusion of Public Health PBRNs}

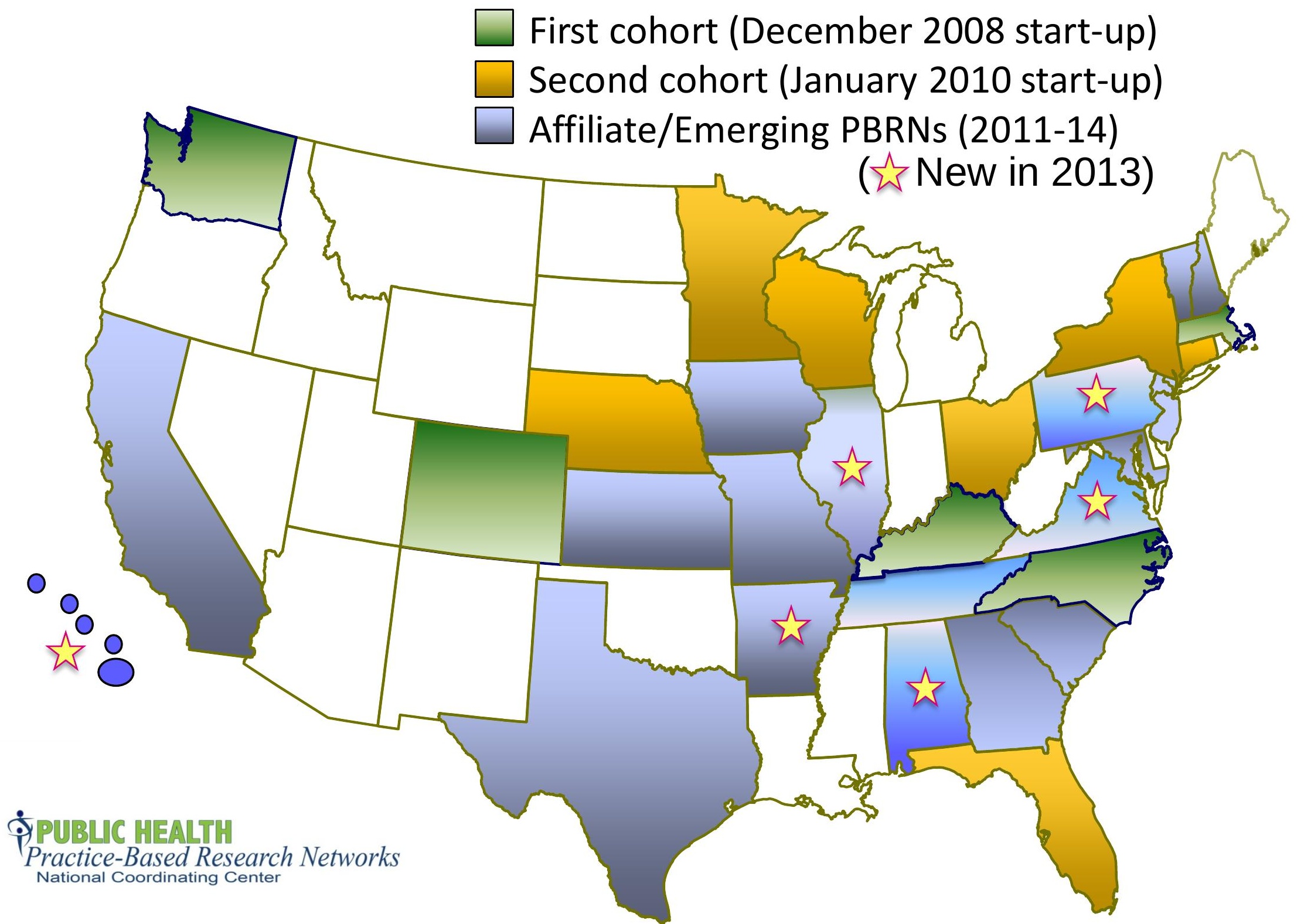




\section{Studying Production Processes}

Multi-Network Practice and Outcome Variation (MPROVE) Study, 2013-14

Measures of Interest

- Availability/Scope: specific activities produced

- Volume/Intensity: Frequency of producing activity over period of time

- Capacity: Labor and capital inputs assigned to an activity

- Reach: Proportion of target population reached by activity

- Quality: effectiveness, timeliness, equity of activity

- Efficiency: resources required to produce given volume of activity 
MPROVE Example: Implementation of community-wide health education campaigns to promote physical activity

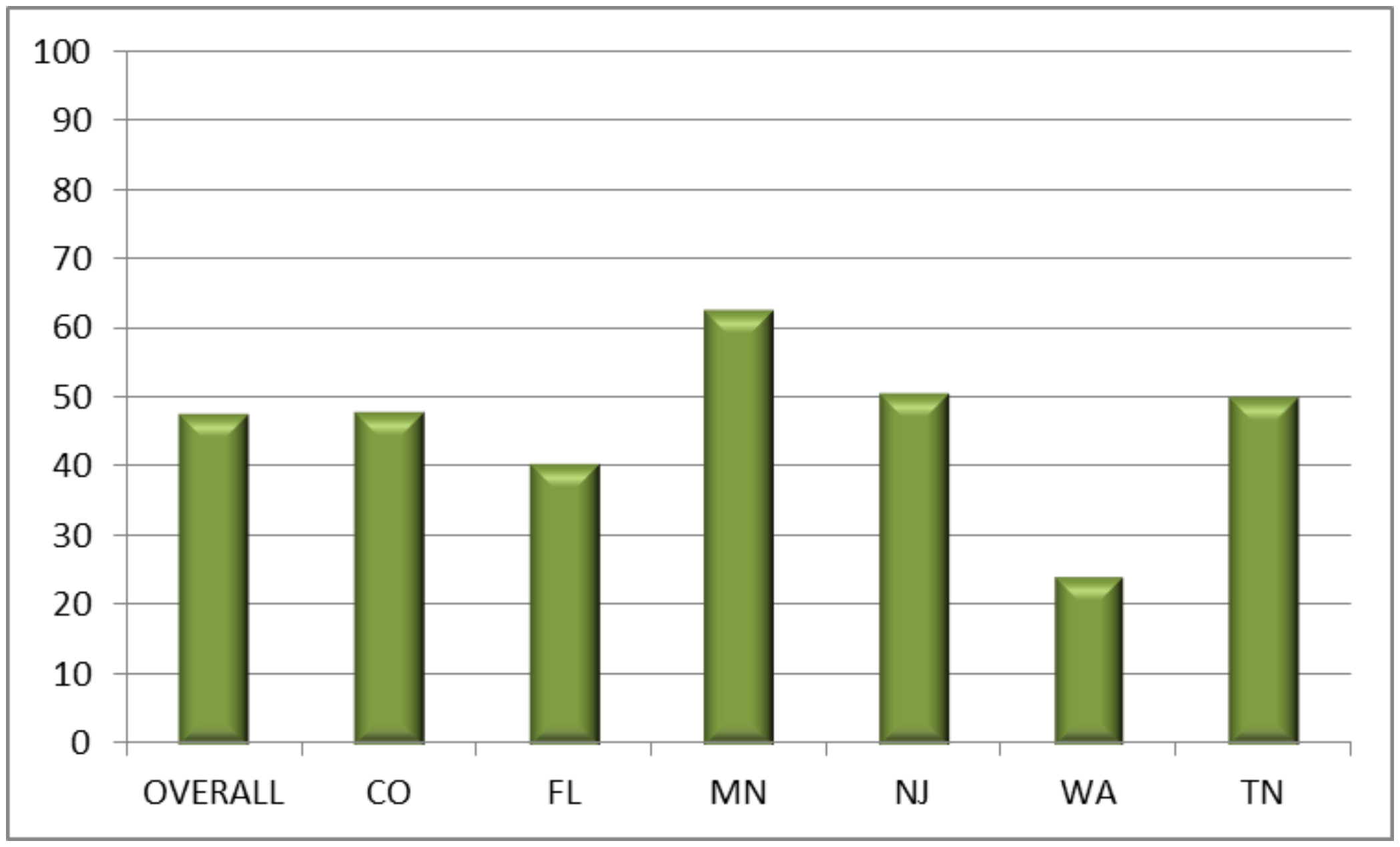


MPROVE Example: Implementation of educational interventions to reduce tobacco use and/or exposure

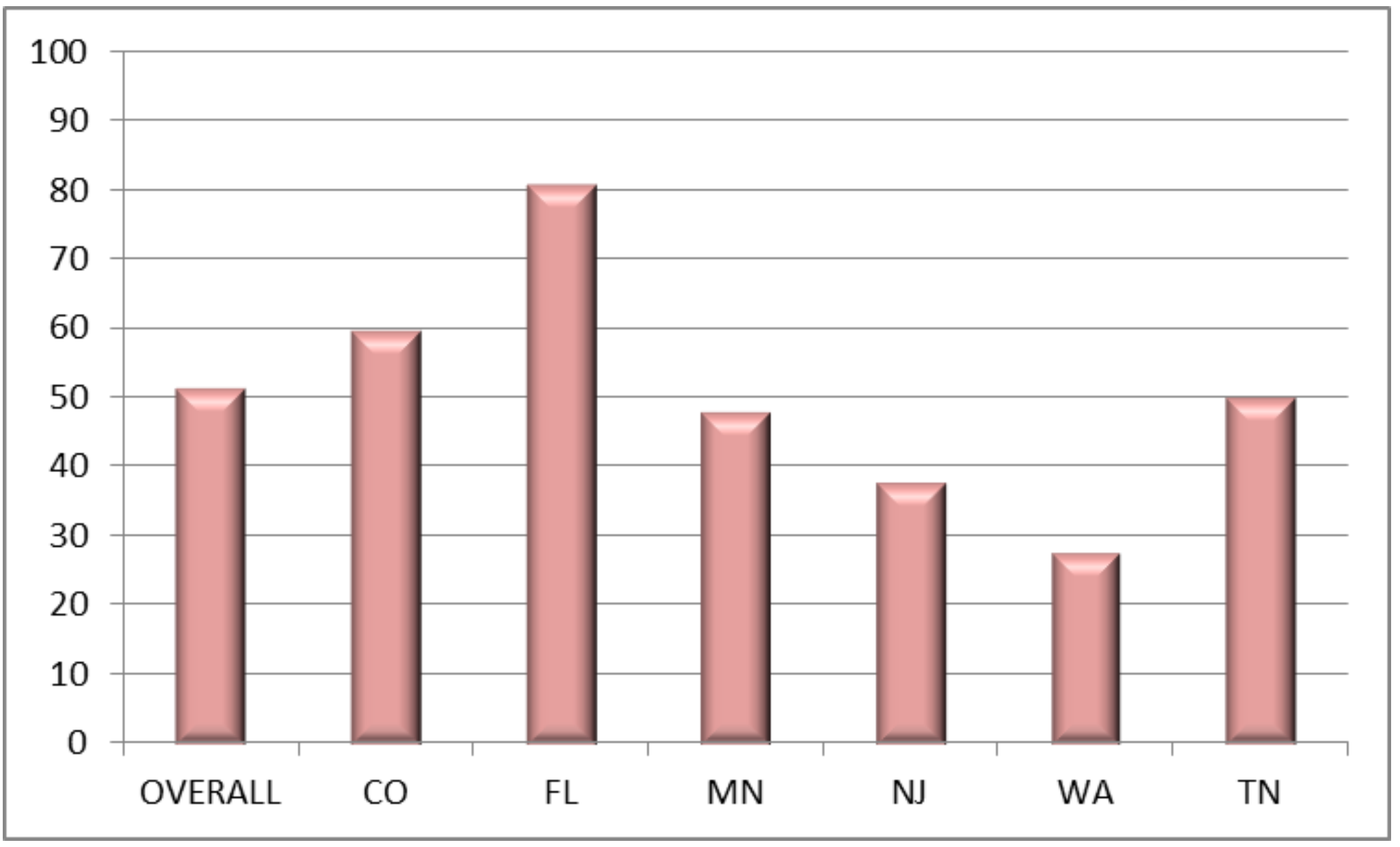




\section{Toward a "rapid-learning system" in public health}

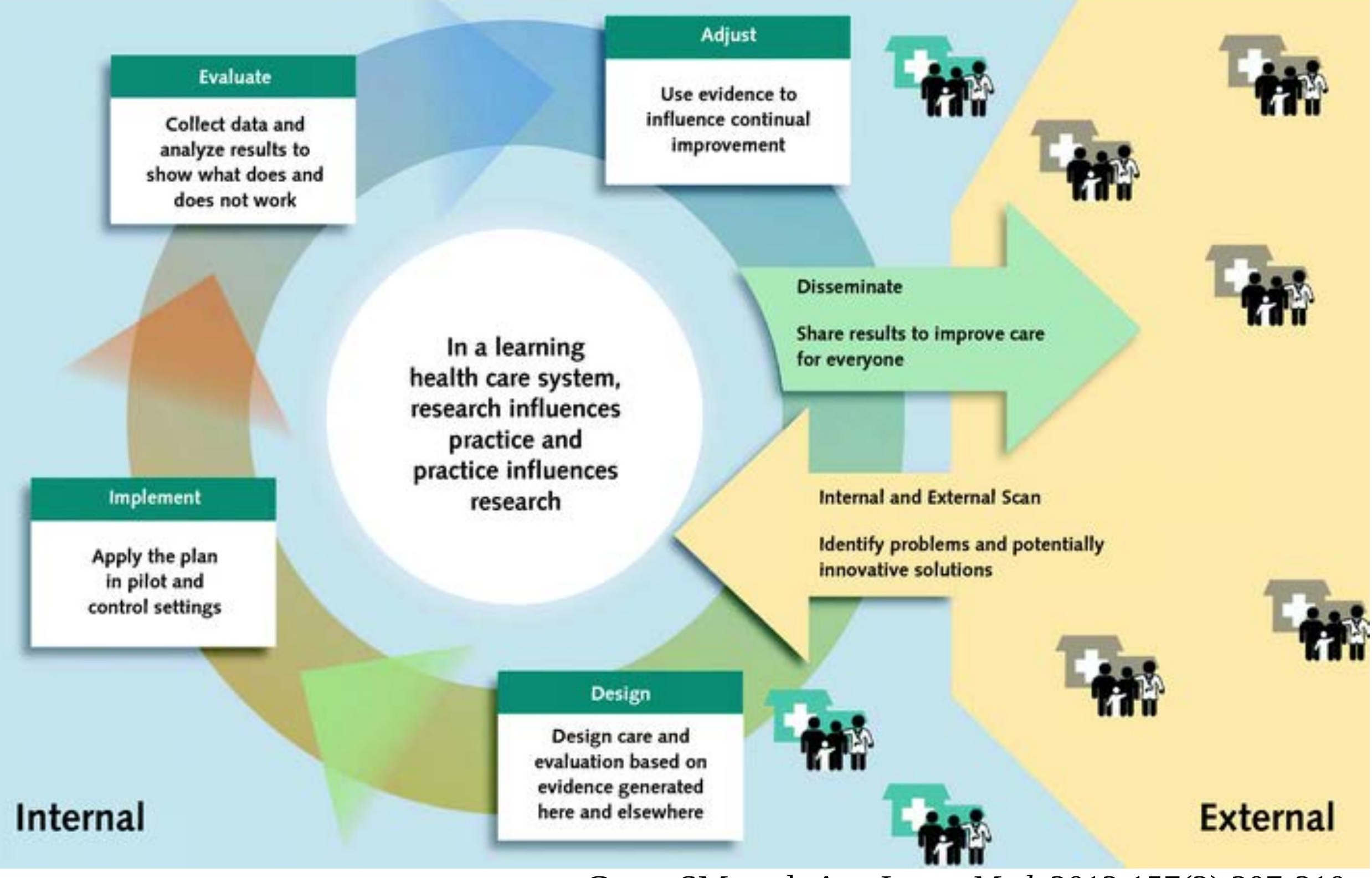

Green SM et al. Ann Intern Med. 2012;157(3):207-210 


\section{Always Open}

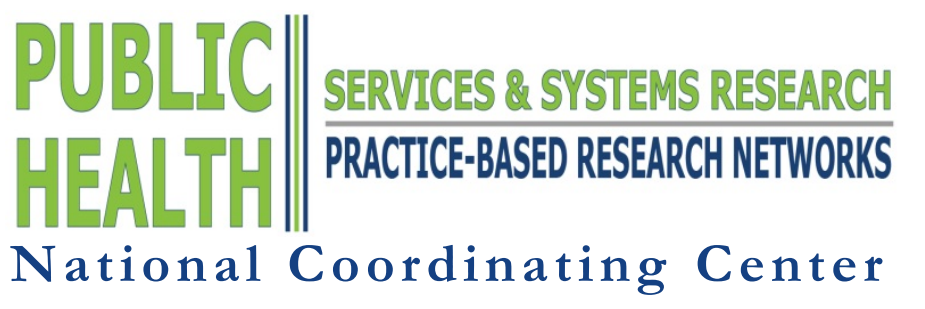

Supported by The Robert Wood Johnson Foundation

$$
\begin{gathered}
\text { Glen P. Mays, Ph.D., M.P.H. } \\
\text { glen.mays@uky.edu }
\end{gathered}
$$

Email: publichealthPBRN@uky.edu Web: www.publichealthsystems.org

Journal: www.FrontiersinPHSSR.org Archive: works.bepress.com/glen_mays Blog: publichealtheconomics.org

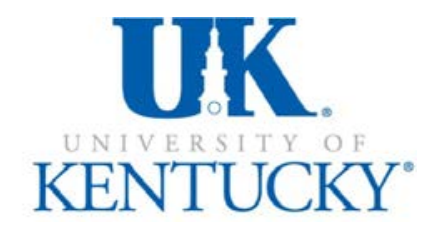

